$\mathrm{DOE} / \mathrm{MC} / 10637--2827-\mathrm{Task}-5.1$

DE92 007531

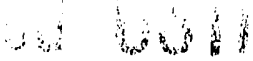

051902

\title{
DIRECT LIQUEFACTION OF LOW-RANK COALS
}

Annual Technical Report for the Period Apri1 1, 1987-March 31, 1988 including the

Quarterly Technical Progress Report for the Period January through March 1988

by

John R. Rindt, Melanie D. Hetland, Curtis L. Knudson, and Warrack G. Willison University of North Dakota Energy and Mineral Research Center

P.0. Box 8213, University Station

Grand Forks, North Dakota 58202

April 1988

Contracting Officer's Technical Representative: William E. Mckinstry

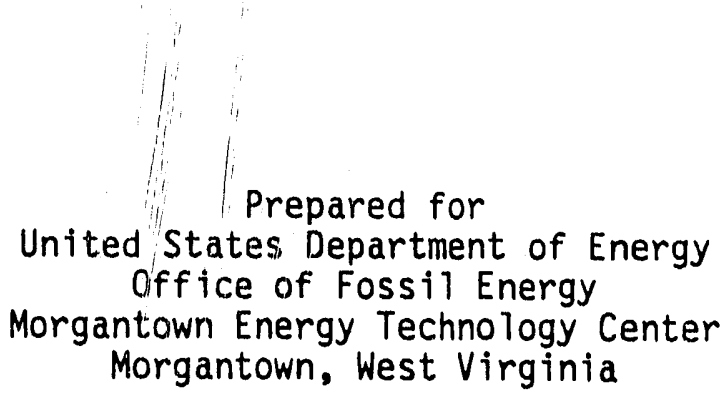

Under Cooperative Agreement No. DE-FC21-86MC10637

\section{DISCLAIMER}

This report was prepared as an account of work sponsored by an agency of the United States Government. Neither the United States Government nor any agency thereof, nor any of their employees, makes any warranty, express or implied, or assumes any legal liability or responsibility for the accuracy, completeness, or usefulness of any information, apparatus, product, or process disclosed, or represents that its use would not infringe privately owned rights. Reference herein to any specific commercial product, process, or service by trade name, trademark, manufacturer, or otherwise does not necessarily constitute or imply its endorsement, recommendation, or favoring by the United States Government or any agency thereof. The views and opinions of authors expressed herein do not necessarily state or reflect those of the United States Government or any agency thereof. 


\subsection{Low-Rank Coal Direct Liquefaction}




\section{DIRECT LIQUEFACTION OF LOW-RANK COALS}

Annual Technical Report for the Period April 1, 1987-March 31, 1988 including the

Quarterly Technical Progress Report for the Period January through March 1988

by

John R. Rindt, Melanie D. Hetland, Curtis L. Knudson, and Warrack G. Willson University of North Dakota Energy and Mineral Research Center

P.0. Box 8213, University Station

Grand Forks, North Dakota 58202

April 1988

Contracting Officer's Technical Representative: William E. McKinstry

Prepared for

United States Department of Energy

Office of Fossil Energy

Morgantown Energy Technology Center

Morgantown, West Virginia

Under Cooperative Agreement No. DE-FC21-86MC10637 


\section{DISCLAIMER}

"This report was prepared as an account of work sponsored by an agency of the United States Government. Neither the United States Government nor any agency thereof, nor any of their employees, makes any warranty, express or implied, or assumes any legal liability or responsibility for the accuracy, completeness, or usefuliness of any information, apparatus, product, or process disclosed, or represents that its use would not infringe privately owned rights. Reference herein to any specific commercial product, process, or service by trade name, trademark, manufacturer, or otherwise, does not necessarily constitute or imply its endorsement, recommendation, or favoring by the United States Government or any agency thereof. The views and opinions of authors expressed herein do not necessarily state or reflect those of the United States Government or any agency thereof."

This report has been reproduced directly from the best available copy.

Available from the National Technical Information Service, U.S. Department of Commerce, Springfield, Virginia 22161. 
LIST OF TABLES $\ldots \ldots \ldots \ldots \ldots \ldots \ldots \ldots \ldots \ldots \ldots \ldots \ldots \ldots \ldots \ldots \ldots \ldots \ldots \ldots \ldots$

LIST OF FIGURES..................................

EXECUTIVE SUMMARY................................. v

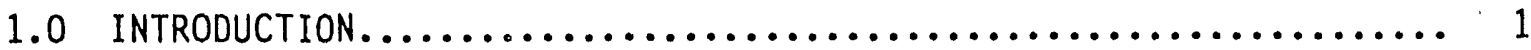

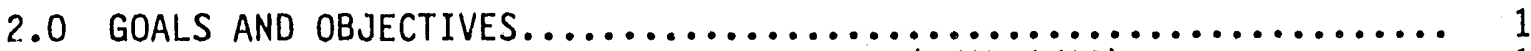

2.1 Proposed Work for the Second Year $(4 / 87-3 / 88) \ldots \ldots \ldots \ldots \ldots \ldots 1$

2.1.1 Task 1 - Co-processing of Low-Rank Coals........... 1

2.1.2 Task 2 - ChemCoal Process......................... 1

2.1.3 Task 2 - Agglomeration Studies................... 2

2.2 Change of Scope................................. 3

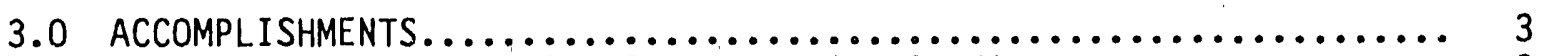

3.1 Results of Task 1 - Co-processing Studies................ 3

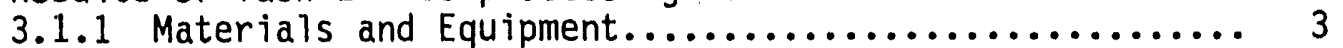

3.1.2 Results of Autoclave Testing.................. 5

3.1.2.1 Catalyst-Screening Runs N377, N379,

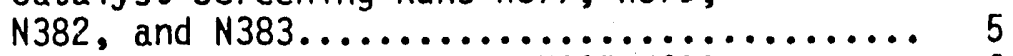

3.1.2.2 Conditions-Screening Runs N385-N389........ 6

3.1.3 Conclusions and Recommendations................. 6

3.2 Results of Task 2 - ChemCoal Program................... 9

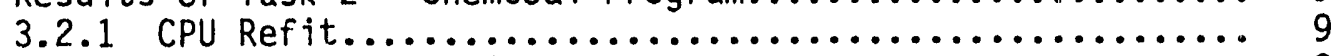

3.2.2 Downstream Modifications....................... 9

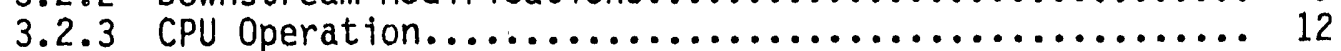

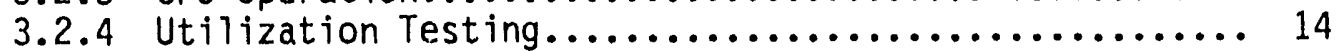

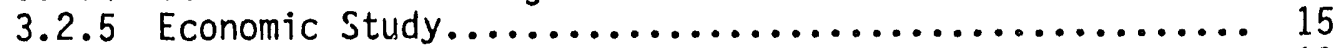

3.2.6 Conclusions and Recommendations..................... 18

3.3 Results of Task 2 - Agglomeration Studies................. 18

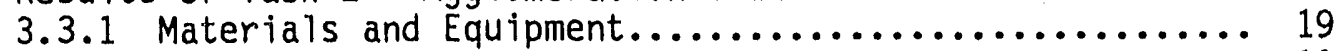

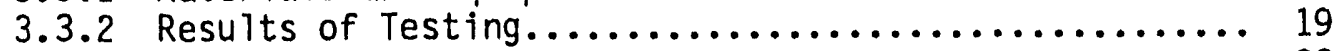

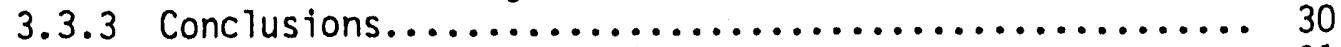

3.4 Papers Presented for Presentation................... 31

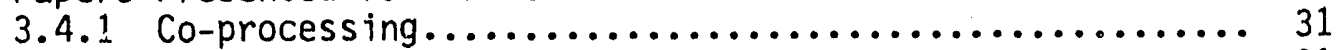

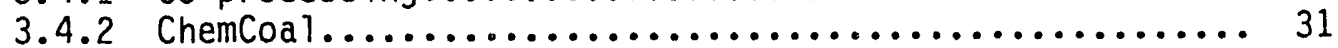

3.4 .3 Agglomeration................................ 32

4.0 CONCLUSIONS AND RECOMMENDATIONS ..................... 32

4.1 Task 1 - Co-processing of Low-Rank Coal.................. 32

4.2 Task 2 - ChemCoal Process.............................. 33

4.3 Task 3 - Agglomeration Studies...................... 33

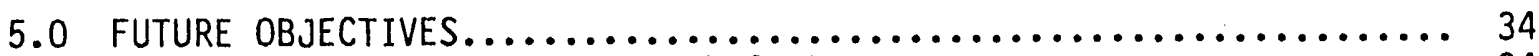

5.1 Co-processing of Low-Rank Coal.................... 34

5.2 ChemCoal Process.................................. 34

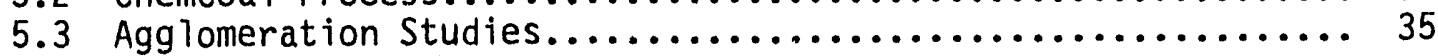

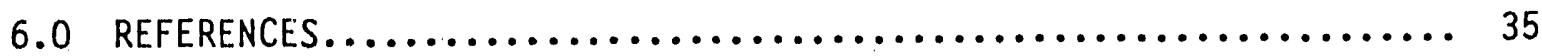




\section{LIST OF TABLES}

Table

Page

1. Summary of nominal run conditions of staged autoclave co-processing tests using Mart in Lake lignite............... 4

2. Metals content based on pentane solubility................. 5

3. Metals content based on percent product slurry distillable..... 7

4. Product metals content as a function of pentane solubility...... 8

5. Results of analytical testing performed on products of staged autoclave co-processing tests using Martin Lake lignite......... 8

6. Nominal CPU ChemCoal run conditions...................... 12

7. Comparison of UNDEMRC ChemCoal with Allison's target fuel specifications for bench-scale combustor testing............. 14

8. Microagglomeration results for -325 mesh Illinois \#6 bituminous coal, as received.......................... 21

9. Microagglomeration results for $70 \mathrm{wt} \%-200$ mesh Illinois \#6 bituminous coal, as received......................... 22

10. Agglomeration results for $50 \mathrm{wt} \%$ Mandan Decant $0 i 1$ in p-xylene and $70 \mathrm{wt} \%-200$ mesh Illinois \#6 bituminous coal, as received.... 23

11. Microagglomeration results for -325 mesh Indian Head lignite,

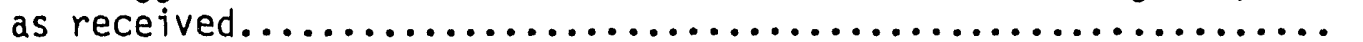

12. Microagglomeration results for -325 mesh Indian Head lignite,

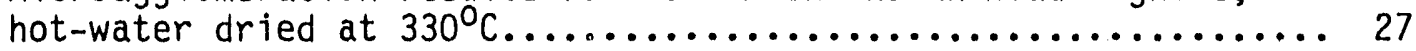

13. Agglomeration results for $50 \mathrm{wt} \%$ Mandan Decant $0 i 1$ in p-xylene and -325 mesh Indian Head lignite, hot-water dried at $330^{\circ} \mathrm{C} \ldots \ldots 28$

14. Agglomeration results for $50 \mathrm{wt} \%$ Mandan Decant Binding $0 i 1$ and -325 mesh Indian Head lignite, as received. 


\section{LIST OF FIGUIRES}

Figure

Page

1. Staged batch autoclave system used during co-processing studies. 3

2. Layout of CPU operations area before and after the refit....... 10

3. Flowsheet of the improved CPU layout.................... 11

4. Flowsheet of new CPU ChemCoal distillation system............ 13

5. Feed coal (a) and ChemCoal product (b) - Magnification $=50 \times \ldots . .15$

6. Feed coal (a) and ChemCoal product (b) - Magnification $=100 \times \ldots .16$

7. Feed coal (a) and ChemCoal product (b) - Magnification $=500 x \ldots 16$

8. Feed coal (a) and ChemCoal product (b) - Magnification $=1000 \times \ldots 17$

9. ChemCoal product - Magnification $=5000 x \ldots \ldots \ldots \ldots \ldots \ldots \ldots \ldots$

10. Discrete agglomerates formed from -200 mesh, as-received Illinois \#6 bituminous coal and 50 wt\% Mandan Decant 011

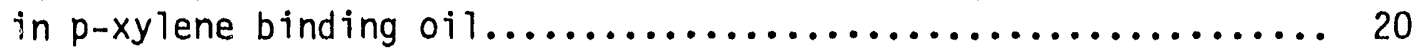

11. Amalgam agglomerate formed from -200 mesh, as-received I11inois \#6 bituminous coal and 50 wt\% Mandan Decant $0 i 1$

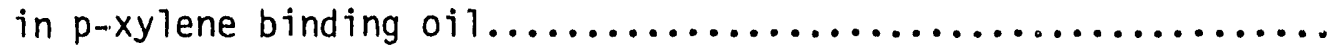

12. Percent agglomerate ash (moisture-free basis) as a function of solvent-to-coal ratio for 3- and 6-minute mixing periods. Mandan Decant $0 i 1$ in $p-x y l e n e$ binder and bituminous coal

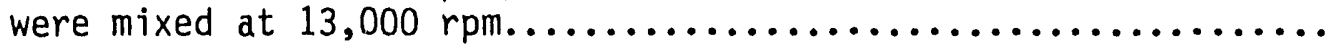

13. Percent agglomerate ash (moisture-free basis) as a function of solvent-to-coal ratio for 3- and 6-minute mixing periods. Mandan Decant $0 i 1$ in $p$-xylene binder and bituminous coal

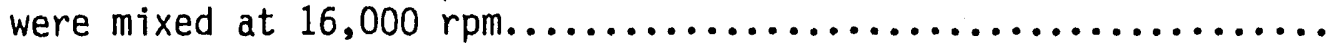

14. Percent agglomerate ash (moisture-free basis) as a function of solvent-to-coal ratio for mixing speeds of 13,000 and $16,000 \mathrm{rpm}$. Maridan Decant $0 i 1$ in $\mathrm{p}-x y$ lene binder and

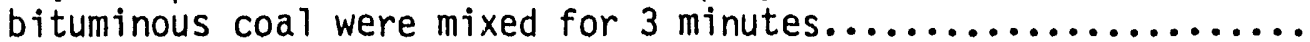

15. Percent agglomerate ash (moisture-free basis) as a function of solvent-to-coal ratio for mixing speeds of 13,000 and $16,000 \mathrm{rpm}$. Mandan Decant $0 i 1$ in $\mathrm{p}-\mathrm{xy}$ lene binder and bituminous coal were mixed for 6 minutes. 


\section{LIST OF FIGURES}

\section{Figure}

16. Percent agglomerate ash (moisture-free basis) as a function of solvent-to-coal ratio for both 70 wt\% -200 mesh and -325 mesh bituminous coal. Mixing speed was $16,000 \mathrm{rpm}$ for 6 minutes...... 26

17. Percent agglomerate ash (moisture-free basis) as a function of solvent-to-coal ratio for -325 mesh as-received and hot-waterdried lignite. Mixing speed was $10,000 \mathrm{rpm}$ for 3 minutes....... 29

18. Percent agglomerate ash (moisture-free basis) as a function of solvent-to-coal ratio for 10,000 and $20,000 \mathrm{rpm}$ mixing speeds. Mandan Decant $0 i 1$ in $p-x y$ lene binder and lignite were mixed

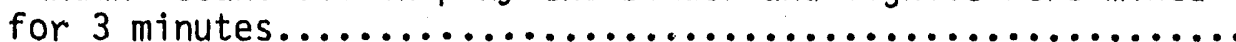




\section{EXECUTIVE SUMMARY}

Research was performed during the year in three major areas: co-processing of low-rank coals with petroleum resids, the ChemCoal Process, and $0 i 1$ agglomeration.

The University of North Dakota Energy and Mineral Research Center (UNDEMRC) research concluded that co-processing appears to have merit as a means of reducing catalyst-poisoning metals concentrations in petroleum resids. It was found that pentane extraction of the product slurry provides a greater yield of usable product than distillation, and the pentane-soluble product contains iron, nickel, and vanadium in concentrations comparable to those of the distillate product. The most successful test in terms of product yield and composition appears to have been a low-temperature first-stage/hightemperature second-stage system. The use of the high-temperature firststage/low-temperature second-stage system commonly used with most bituminous coals does not appear to be as successful for low-rank coals (LRCs) with respect to desired product composition. It was concluded that, to properly evaluate co-processing, both coal conversion and the extent of upgrading need to be assessed in terms of reaction cost and product value.

The majority of the work performed on the Chemcoal Process concentrated on redesign of the system reactor and downstream processing areas, as well as the associated refit of equipment. The new designs appear to have had the desired effects of shortening reactor residence times and producing Chemcoal product on line. In addition, the new CPU layout has resulted in a significant decrease in odor in the work area. Chemcoal processing results in a product with a smaller mean particle size than the feed due to the formation of floccules. The Chemcoal solid which was prepared by acidification and shipped to Allison Gas Turbine Division appears to be superior in nearly every respect to ultra-clean coal, although it contained $0.48 \%$ ash.

During agglomeration studies, it was found that more ash was removed from coals of finer particle size than from larger particle sizes, and hotwater-dried lignite appeared to liberate ash more easily than did as-received lignite. Medium-density solvents seemed to reduce ash more effectively during agglomeration than high-density solvent, and greater ash reductions were realized with higher mixing speeds and longer mixing times. It was also found that agglomerates which are flocculate or discrete in form generally produced greater ash reductions than did amalgam agglomerates. 


\section{DIRECT LIQUEFACTION OF LOW-RANK COALS}

\subsection{INTRODUCTION}

(1) Co-processing of low-rank coals (LRCS) with petroleum resids under mild conditions may produce a product that extends petroleum refinery feeds with a partially coal-derived material. These co-processing products may also provide a lower-cost way to introduce coal-derived materials into the commercial market. In this staged process, the petroleum resid acts as a solvent, aiding in the solubilization of the coal during the first stage, and both the dissolved coal and the resid are upgraded during a second-stage catalytic hydrogenation.

Another method of upgrading coal in a liquefaction process is the Chemcoal Process. The process uses chemical methods to transform coal into clean solid and liquid products. It features low-severity coriversion of coal in a phenolic solvent, using an alkali promotor and carbon monoxide as the reductant.

0 il agglomeration has been used to reduce the ash and mineral matter in bituminous coals to obtain a product with increased heating value, reduced moisture, and lower sulfur content. This method can be used to produce a clean coal feedstock for liquefaction. During agglomeration, an oil is used to preferentially wet the organic phases of the coal, and water is used to wet the minerals, resulting in a separation of ash and water from the coal.

\subsection{GOALS AND OBJECTIVES}

The primary objective of this project is to expand the scientific and engineering data base of LRC liquefaction by investigating direct liquefaction processes that will produce the most competitive feedstocks or liquid fuels. The work effort which was proposed for the second year of this cooperative agreement dealt primarily with co-processing and the ChemCoal Process

\subsection{Proposed Work for the Second Year (4/87-3/88)}

\subsubsection{Task 1 - Co-Processing of Low-Rank Coal}

An engineering evaluation was planned to assess continuous process unit (CPU) operability in a two-stage system as well as conversion/yield structure for the lignite/resid combination selected during FY 86/87. Both routine analysis of the products for engineering material balance information and detailed analytical support were determined to be necessary to assess the application of staged co-processing to lignite. Detailed characterizations of both feed and product streams were slated to include NMR, GC/MS, and metals analyses.

\subsubsection{Task 2 - ChemCoal Process}

The ChemCoal Process has been identified as a process with the potential for producing a clean product at competitive prices. This process was successfully demonstrated at the University of North Dakota Energy and Mineral 
Research Center (UNDEMRC) in 1986 during a recycle test. The results of this test indicated that additional research on the ChemCoal Process would be beneficial. Work effort proposed for the FY $87 / 88$ ChemCoal program included a repeat of the initial recycle test, the production and testing of ChemCoal product in gas turbine and/or diesel engines, and an updating of the process economics.

To accomplish these goals, it was considered necessary to update the reactor portion of the CPU in terms of permanent reinstallation of equipment, system controls, and data acquisition system. This was necessary primarily to improve safety and reliability and for long-term operation. The activity was considered to be part of routine maintenance, although it was expected that it would take two or more months to complete.

Plans were also made to modify the post-reactor equipment to reflect information acquired during the recycle CPU operation associated with past work at UNDEMRC. The necessary modifications consisted of the installation of a pyrolysis solvent recovery unit, individual solids separation units, and a different distillation unit. It was felt that installation of these units would allow for direct on-line collection of solid Chemcoal particles in addition to a more realistic product slate. This improved downstream equipment and processing was aimed at correcting deficiencies in ash removal and sodium recovery.

CPU operation was planned to provide both process jevelopment data and products for utilization/marketing development. Four to six CPU runs were planned to produce between 150 and 500 pounds of ChemCoal solids for utilization testing. Analytical support necessary for this activity was to be aimed at the development of the Chemcoal Process, especially with respect to answering questions resulting from operations requirements. Specific chemical characterization of the product slate was planned to assist in utilization/ marketing development.

Materials produced during the CPU tests were to be sent to an outside organization for end-use testing as a diesel and/or turbine fuel extender/ substitute.

An in-house economic study was planned to update a previously completed Bechtel study. It was planned that the updated study would feature the effects of the process improvements developed as a result of the last recycle test.

\subsubsection{Task 2 - Agglomeration Studies}

Agglomeration studies comprised the third aspect of the research which was carried out during the FY $87 / 88$ program year. These studies focused on the development of the technical capability to prepare a low-ash LRC feedstock for liquefaction by separation/agglomeration using viscous liquids derived from petroleum, bitumen, or a select Chemcoal Process stream fraction. The resulting easily-handled dry product, high in coal content, was to be separated from an aqueous discharge high in ash content. It was planned that, if the hydrophilic natlire of the raw coals limited the usefulness of this approach, hot-water drying would be used to change the nature of the coal. 


\subsection{Change of Scope}

The DOE's desire to further assess the ChemCoal Process and to support continued process development led to a change in program direction. Twothirds of the FY 87/88 Cooperative Agreement funding which was originally slated for co-processing use was diverted to the development of the ChemCoal Process. This resulted in the performance of autoclave (as opposed to continuous) co-processing tests and minimal analysis of the products of these tests. The remainder of the work effort focused on the refit of the CPU and the production of additional Chemcoal product for end-use testing.

\subsection{ACCOMPLISHMENTS}

\subsection{Results of Task 1 - Co-Processing Studies}

\subsubsection{Materials and Equipment}

Five hot-charge, staged, batch autoclave tests were performed to compare "normal" staged liquefaction solvent to "co-processing" solvent. The testing was performed in the staged batch autoclave system pictured in Figure 1 . Al1 of the runs were performed using Martin Lake, Texas, lignite. Three runs were made with A04 solvent, while Lummus solvent was used for one run and Arabian resid was used for the other. Table 1 lists the nominal run conditions for these five tests as well as four tests which were made late in FY 86/87. The data for these runs were reduced during the $87 / 88$ program year.

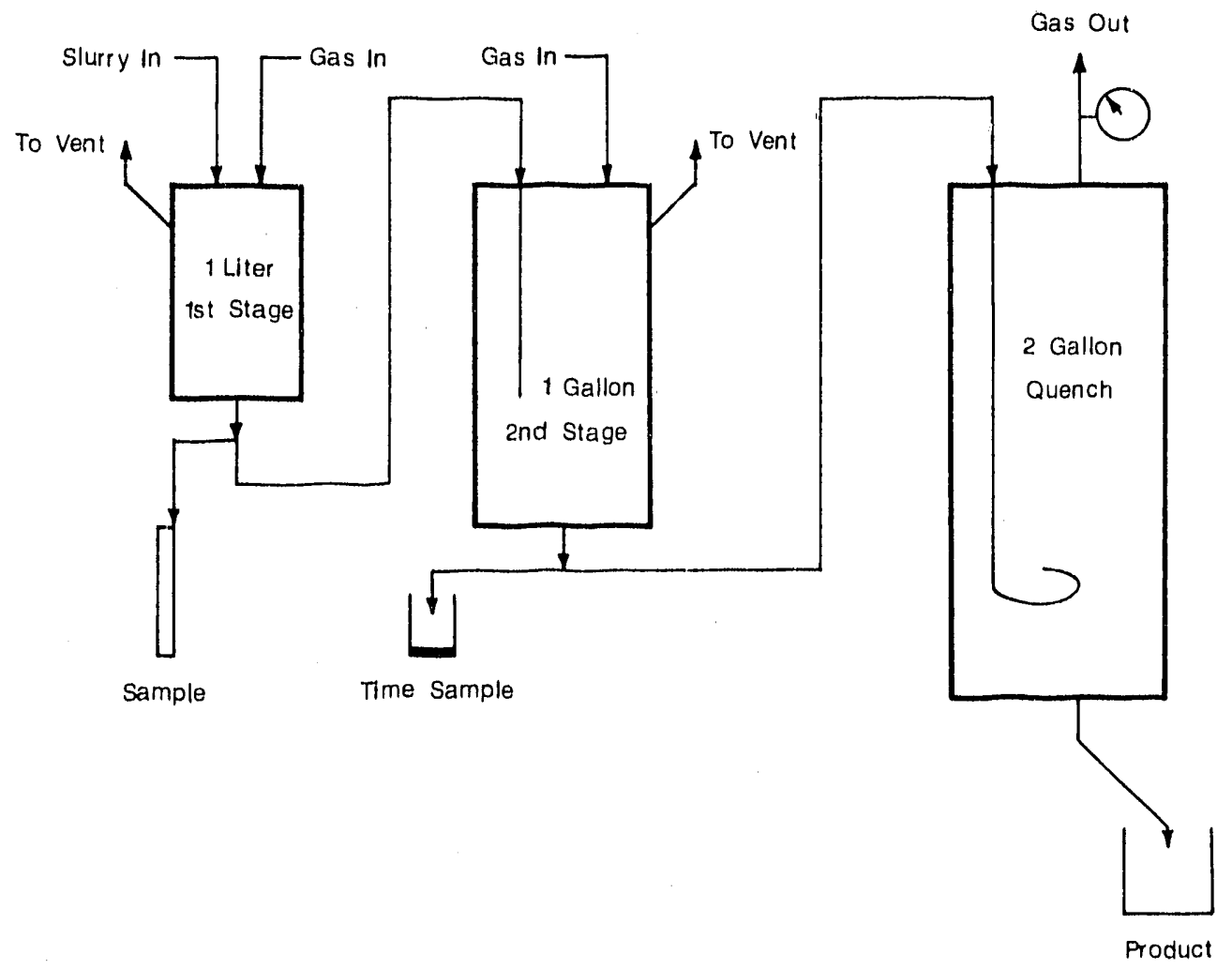

Figure 1. Staged batch autoclave system used during co-processing studies. 


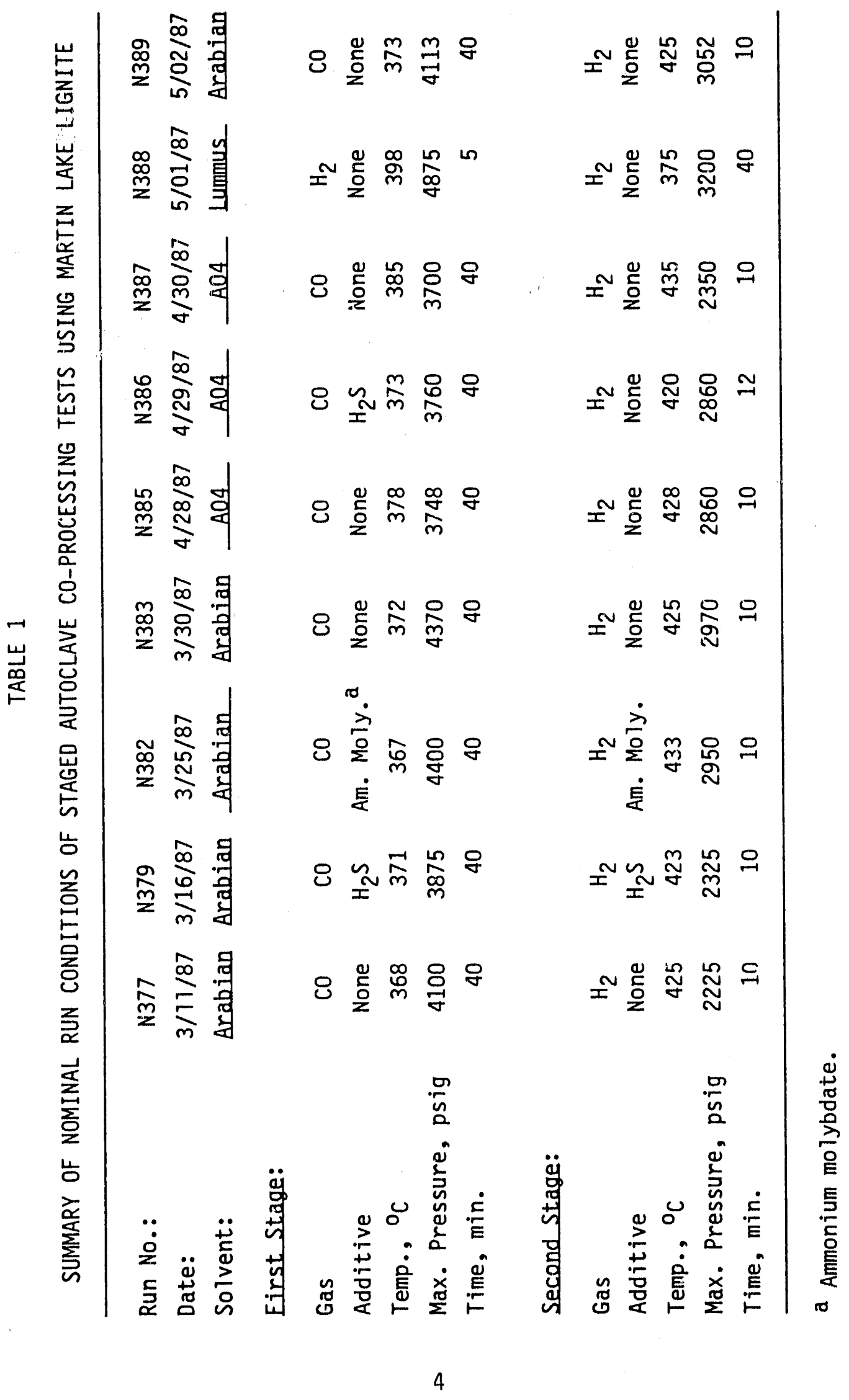




\subsubsection{Results of Autoclave Testing}

\subsubsection{Catalyst-Screening Runs N377, N379, N382, and N383}

The results of the analytical work performed on Runs N377, N379, N382, and N383 were reduced during the first quarter of FY 87/88. Run feedstocks and conditions are given in Table 1. The following paragraphs provide an overview of these results.

Determination of trace heavy metals concentrations in the co-processing products was carried out as a function of pentane solubility. Samples of the product slurries from Runs N379, N382, and N383 were separated into pentanesoluble and insoluble fractions. Both fractions, as well as the raw product slurries from each test, were analyzed for iron, nickel, and vanadium using an acid digestion technique. The data in Table 2 show that the product slurry of the uncatalyzed run contained more iron than did either the $\mathrm{H}_{2} \mathrm{~S}$ - or ammonium molybdate-catalyzed runs, while its nickel and vanadium contents were only slightly higher.

TABLE 2

METALS CONTENT BASED ON PENTANE SOLUEILITY

\begin{tabular}{|c|c|c|c|c|}
\hline & & $\mathrm{Fe}(\mathrm{ppm})$ & $\mathrm{Ni}$ (ppm) & $V(p p m)$ \\
\hline N379 & $\begin{array}{l}\text { product slurry } \\
\text { pentane solubles } \\
\text { pentane insolubles }\end{array}$ & $\begin{array}{r}1,700 \\
0 \\
13,000\end{array}$ & $\begin{array}{r}45 \\
0 \\
190\end{array}$ & $\begin{array}{r}91 \\
6 \\
370\end{array}$ \\
\hline N382 & $\begin{array}{l}\text { product slurry } \\
\text { pentane solubles } \\
\text { pentara insolubles }\end{array}$ & $\begin{array}{r}1,800 \\
17 \\
16,000\end{array}$ & $\begin{array}{r}47 \\
4 \\
210\end{array}$ & $\begin{array}{r}70 \\
6 \\
360\end{array}$ \\
\hline N383 & $\begin{array}{l}\text { product slurry } \\
\text { pentane solubles } \\
\text { pentane insolubles }\end{array}$ & $\begin{array}{r}2,400 \\
46 \\
13,000\end{array}$ & $\begin{array}{r}57 \\
0 \\
180\end{array}$ & $\begin{array}{r}100 \\
5 \\
380\end{array}$ \\
\hline $\begin{array}{l}\text { Arabi } \\
\text { Marti }\end{array}$ & $\begin{array}{l}\text { ian resid raw } \\
\text { pentane solubles } \\
\text { in Lake coal }\end{array}$ & $\begin{array}{r}56 \\
0 \\
4,300\end{array}$ & $\begin{array}{r}37 \\
8 \\
0\end{array}$ & $\begin{array}{r}120 \\
28 \\
24\end{array}$ \\
\hline $\begin{array}{l}\text { NBS } 8 \\
\text { NBS } 1\end{array}$ & 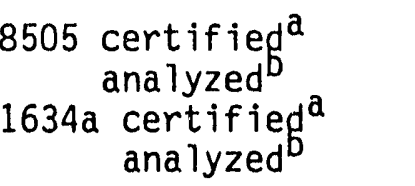 & $\begin{array}{l}-- \\
-- \\
31\end{array}$ & $\begin{array}{l}-- \\
29 \\
31\end{array}$ & $\begin{array}{r}390 \\
460 \\
56 \\
61\end{array}$ \\
\hline
\end{tabular}

a Values certified by National Bureau of Standards.

$b$ values obtained using described analysis. 
The effect of co-processing on the trace heavy metals concentrations was also examined as a function of percent distillable product slurry. Vacuum distillations were carried out to obtain these data. The results of these analyses are presented in Table 3, which shows that the trace heavy metals were indeed concentrated in the residue, as would be expected. For the most part, the $120^{\circ}-260^{\circ} \mathrm{C}$ cut cantained more iron than did the other distillation cuts with the exception of the residue. Nickel and vanadium values were higher for all runs in the $260^{\circ}-275^{\circ} \mathrm{C}$ cut than in the $120^{\circ}-260^{\circ} \mathrm{C}$ cut.

Pentane extraction and distillation were compared as methods of recovering the largest product yield with the lowest metals concentrations possible. Table 4 presents product metals contents as a function of pentane solubility, along with coal conversions achieved for Runs N379, N382, and N383. These data suggest that co-processing may reduce the nickel and vanadium concentrations in the pentane-soluble fraction of Arabian resid.

These results are reported in a paper which was prepared for presentation at the Coal-0il Co-Processing Symposium to be held at the Third Chemical Congress of North America sponsored by the American Chemical Society. It will be held in Toronto from June $5-11$, 1988. The abstract of the paper is included in Subsection 3.4 .1 of this report.

\subsubsection{Conditions-Screening Runs N385-N389}

Table 5 presents the results of the analyses initially performed on the five autoclave co-processing runs which were made early in the first quarter of FY 87/88. Runs $N 385$ and N386 were performed to compare the results of processing Martin Lake lignite and $\mathrm{AO} 4$ at similar conditions with and without H2S. Run $N 387$ was performed at slightly higher temperatures and a lower second-stage pressure. Run $\mathrm{N} 388$ was performed to compare the processing used with high-rank coals (high-temperature first stage) with LRC processing (lowtemperature first stage). As the clata in Table 5 show, the carbon content of the Run $N 388$ product was significantly lower than thi carbon contents of the products of the other runs. Run $\mathrm{N} 389$ was a base-case run which was performed when a new barrel of Martin Lake lignite was opened.

Further data and results of these tests will be obtained at a later date. The acquisition of the new data reduction system has been in progress for the last half of FY $87 / 88$, although on a low-priority basis. Due to the change in program direction, this data will not be needed until the second half of $F Y$ 88/89. At that time it will be used to establish conditions for screening tests which will be performed on the CPU.

\subsubsection{Conclusions and Recommendations}

On the basis of preliminary study, co-processing appears to have merit as a means of reducing catalyst-poisoning metals concentrations in petroleum resids. However, in order to properly evaluate co-processing, both coal conversion and the extent of resid upgrading need to be assessed in terms of reaction cost and product value. In addition, a larger, more accurate analytical data base is required to validate the metals concentration values. 
TABLE 3

METALS CONTENT BASED ON PERCENT PRODUCT SLURRY DISTILLABLE

\begin{tabular}{|c|c|c|c|c|}
\hline & $\begin{array}{c}\text { Product Slurry } \\
\text { (wt } \%)\end{array}$ & $\mathrm{Fe}(\mathrm{ppm})$ & $\mathrm{Ni}$ (ppm) & $\underline{V(p p m)}$ \\
\hline $\begin{array}{l}\text { N377 Prod. Slurry } \\
\text { Cold Trap } \\
\text { IBP }-120^{\circ} \mathrm{C} \\
120^{\circ}-260^{\circ} \mathrm{C} \\
260^{\circ}-275^{\circ} \mathrm{C} \\
\text { Residue }\end{array}$ & $\begin{array}{r}9.6 \\
10.3 \\
31.7 \\
6.2 \\
42.2\end{array}$ & $\begin{array}{r}4,200 \\
<5^{\mathrm{a}} \\
<7 \\
7 \\
75 \\
10,200\end{array}$ & $\begin{array}{r}34 \\
<5 \\
<7 \\
4 \\
40 \\
79\end{array}$ & $\begin{array}{r}78 \\
<5 \\
<7 \\
4 \\
40 \\
150\end{array}$ \\
\hline $\begin{array}{l}\text { N379 Prod. Slurry } \\
\text { Cold Trap } \\
\text { IBP }-120^{\circ} \mathrm{C} \\
120^{\circ}-260^{\circ} \mathrm{C} \\
260^{\circ}-285^{\circ} \mathrm{C} \\
\text { Residue }\end{array}$ & $\begin{array}{l}4.4 \\
13.6 \\
27.8 \\
13.8 \\
40.6\end{array}$ & $\begin{array}{r}4,000 \\
<4 \\
<6 \\
55 \\
15 \\
10,200\end{array}$ & $\begin{array}{r}37 \\
<4 \\
<6 \\
4 \\
6 \\
99\end{array}$ & $\begin{array}{r}81 \\
<4 \\
<6 \\
4 \\
6 \\
180\end{array}$ \\
\hline $\begin{array}{l}\text { N382 Prod. Slurry } \\
\text { Cold Trap } \\
\text { IBP }-120^{\circ} \mathrm{C} \\
120^{\circ}-260^{\circ} \mathrm{C} \\
260^{\circ}-305^{\circ} \mathrm{C} \\
\text { Residue }\end{array}$ & $\begin{array}{r}2.2 \\
9.4 \\
30.5 \\
16.1 \\
37.3\end{array}$ & $\begin{array}{r}4,100 \\
<5 \\
<5 \\
12 \\
7 \\
10,800\end{array}$ & $\begin{array}{r}39 \\
<5 \\
<5 \\
4 \\
6 \\
94\end{array}$ & $\begin{array}{r}75 \\
<5 \\
<5 \\
4 \\
6 \\
170\end{array}$ \\
\hline $\begin{array}{l}\text { N383 Prod. Slurry } \\
\text { Cold Trap } \\
\text { IBP }-120^{\circ} \mathrm{C} \\
120^{\circ}-260^{\circ} \mathrm{C} \\
260^{\circ}-285^{\circ} \mathrm{C} \\
\text { Residue }\end{array}$ & $\begin{array}{r}2.7 \\
14.6 \\
31.8 \\
14.1 \\
36.8\end{array}$ & $\begin{array}{r}2,700 \\
<5 \\
<5 \\
74 \\
9 \\
10,500\end{array}$ & $\begin{array}{r}30 \\
<5 \\
<5 \\
5 \\
5 \\
130\end{array}$ & $\begin{array}{r}65 \\
<5 \\
<5 \\
5 \\
5 \\
260\end{array}$ \\
\hline $\begin{array}{l}\text { Resid } \\
120^{\circ}-260^{\circ} \mathrm{C} \\
260^{\circ}-295^{\circ} \mathrm{C} \\
\text { Residue }\end{array}$ & $\begin{array}{l}26.1 \\
16.3 \\
57.6\end{array}$ & $\begin{array}{r}1 \\
1 \\
26 \\
14\end{array}$ & $\begin{array}{r}36 \\
2 \\
2 \\
62\end{array}$ & $\begin{array}{r}12 \\
1 \\
2 \\
19\end{array}$ \\
\hline $\begin{array}{l}\text { Coal Digested } \\
\text { Coal Ashed }\end{array}$ & & $\begin{array}{l}3,900 \\
4,000\end{array}$ & $\begin{array}{r}6 \\
31\end{array}$ & $\begin{array}{l}21 \\
22\end{array}$ \\
\hline $\begin{array}{l}\text { NBS 1634a Analyzed } \\
\text { NBS 1634a Certified }\end{array}$ & & $\begin{array}{l}32 \\
31\end{array}$ & $\begin{array}{l}29 \\
29\end{array}$ & $\begin{array}{l}58 \\
56\end{array}$ \\
\hline
\end{tabular}

a Detection limits are based upon sample size and sensitivity of the instrument. Instrument sensitivity is $0.5 \mu \mathrm{g} / \mathrm{ml}$.

NOTE: Since analyzed and calculated values are in reasonable agreement for N377, N379, N382, and the resid, the large differences between values for N383 are probably due to a measurement error. With the exception of $\mathrm{N} 383$, the analyzed and calculated values for iron are very close. 
TABLE 4

PRODUCT METALS CONTENT AS A FUNCTION OF PENTANE SOLUBILITY

\begin{tabular}{|c|c|c|c|c|c|}
\hline & $\begin{array}{c}\text { Pentane } \\
\text { Solubility }(\%)\end{array}$ & $\mathrm{Fe}$ (ppm) & $\mathrm{Ni}(\mathrm{ppm})$ & $\underline{V}(\mathrm{ppm})$ & $\begin{array}{l}\% \text { MAF Coa } 1 \\
\text { Converted }\end{array}$ \\
\hline N379 & 74.6 & 0 & 0 & 6 & 74.7 \\
\hline N382 & 77.4 & 17 & 4 & 6 & 86.8 \\
\hline N383 & 72.7 & 46 & 0 & 5 & 70.8 \\
\hline Resid & 80.3 & 0 & 8 & 28 & -- \\
\hline
\end{tabular}

TABLE 5

RESULTS OF ANALYTICAL TESTING PERFORMED ON PRODUCTS OF STAGED AUTOCLAVE CO-PROCESSING TESTS USING MARTIN LAKE LIGNITE

\begin{tabular}{lrrrrr}
\hline Run No. & \multicolumn{1}{l}{ N385 } & N386 & N387 & N388 & N389 \\
$\% \mathrm{C}$ & 82.7 & 82.9 & 82.0 & 68.8 & 76.8 \\
$\% \mathrm{H}$ & 5.9 & 6.4 & 6.2 & 8.5 & 10.1 \\
$\% \mathrm{~N}$ & 0.8 & 0.6 & 0.4 & 0.1 & 0.2 \\
$\% \mathrm{~S}$ & 0.4 & 0.6 & 0.5 & 0.2 & 3.1 \\
Pentane & & & & & \\
Solubility & 24.9 & 23.8 & 20.9 & 20.5 & 23.4 \\
THFIa & 5.7 & 4.9 & 7.0 & 8.1 & 8.9 \\
\hline
\end{tabular}

a Expressed as a weight percentage of product. 
Pentane extraction of the product slurry provides a greater yield of usable product than does distillation, and the pentane-soluble product contains iron, nickel, and vanadium in concentrations comparable to those of the distillate product.

The run which was performed to test co-processing using a hightemperature first stage and a low-temperature second stage was not successfu1. A cursory scan of the data indicates that the best success was achieved during Run N386, when Martin Lake Tignite and A04 solvent were reacted at a low-temperature first stage and a high-temperature second stage in the presence of $\mathrm{H}_{2} \mathrm{~S}$.

\subsection{Results of Task 2 - ChemCoal Program}

\subsubsection{CPU Refit}

The majority of the ChemCoal work effort was spent on the CPU refit. A complete teardown of the existing system was performed, and the associated equipment was thoroughly cleaned. The existing equipment was evaluated and relocated in the new layout. Necessary replaciement parts and new equipment were ordered and installed. All pressure vessels were resurfaced and a11 pumps rebuilt. New gas and slurry feed systems were designed, as were the downstream processing and data acquisition/control systems. The barricade was prepared and painted, and a new control panel was built. All instrumentation was installed and calibrated. The computer control system was programmed and checks were performed on both the system and the programming. Delays in the installation of the CPU wiring resulted in a 1-2 month accumulated delay in the program.

Figure 2 shows the layout of the CPU operations area before and after the refit. The downstream processing area was enclosed to better eliminate odors in the work environment. The new design of the downstream processing also necessitated the change in layout.

\subsubsection{Downstream Modifications}

A cold-charge autoclave run was performed in the two-galion system to produce material for testing various downstream processing schemes. The results of these tests finalized the design of the improved downstream processing area.

The new design of both the reactor and dowristream processing areas is shown in the flowsheet of Figure 3. The improvements made in the downstream processing system resulted in the on-line processing of Chemcoal product and the recycling of appropriate solvent cuts. Two centrifuges meeting process design specifications (i.e., closed system with bottoms recycle) were ordered for use in this area. One centrifuge was installed in the system. The other was severely damaged during shipping and was returned to the manufacturer. Following its repair, the second centrifuge was also installed in the system. A rotary filter was acquired and readied to serve as a backup for the centrifuges. 


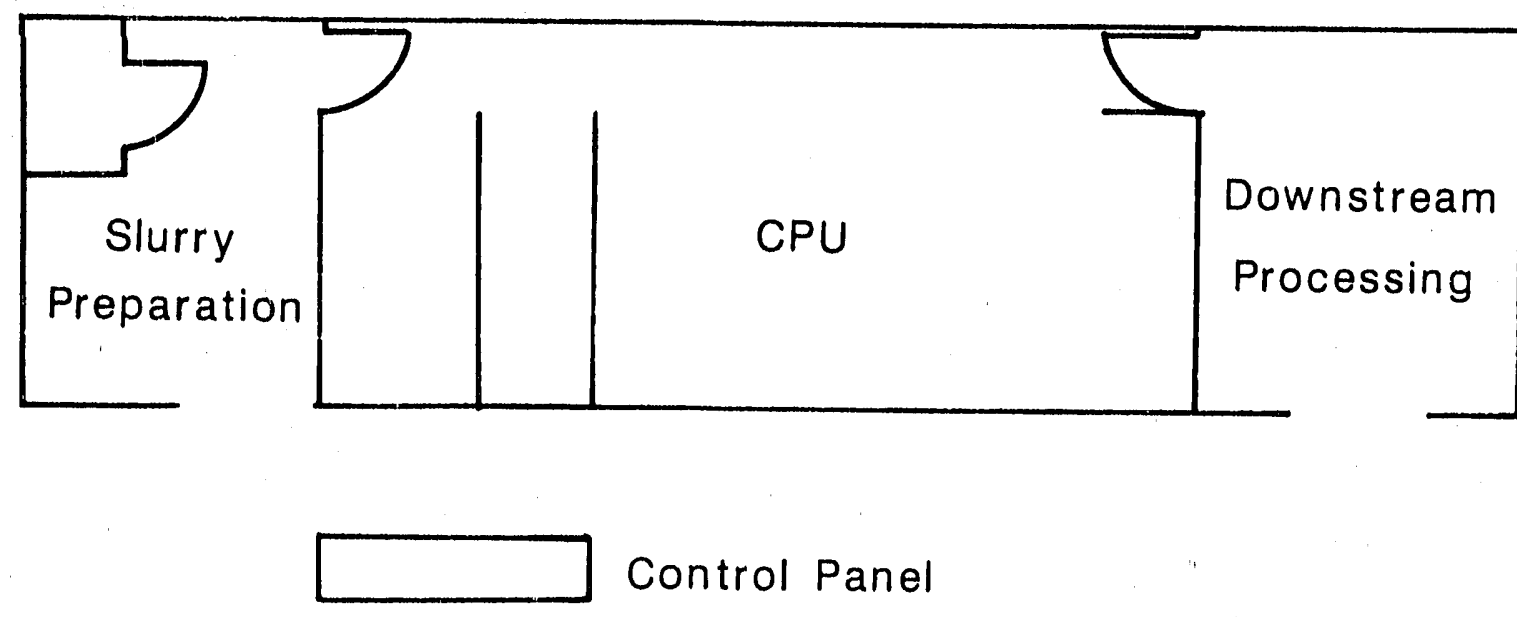

\section{BEFORE}

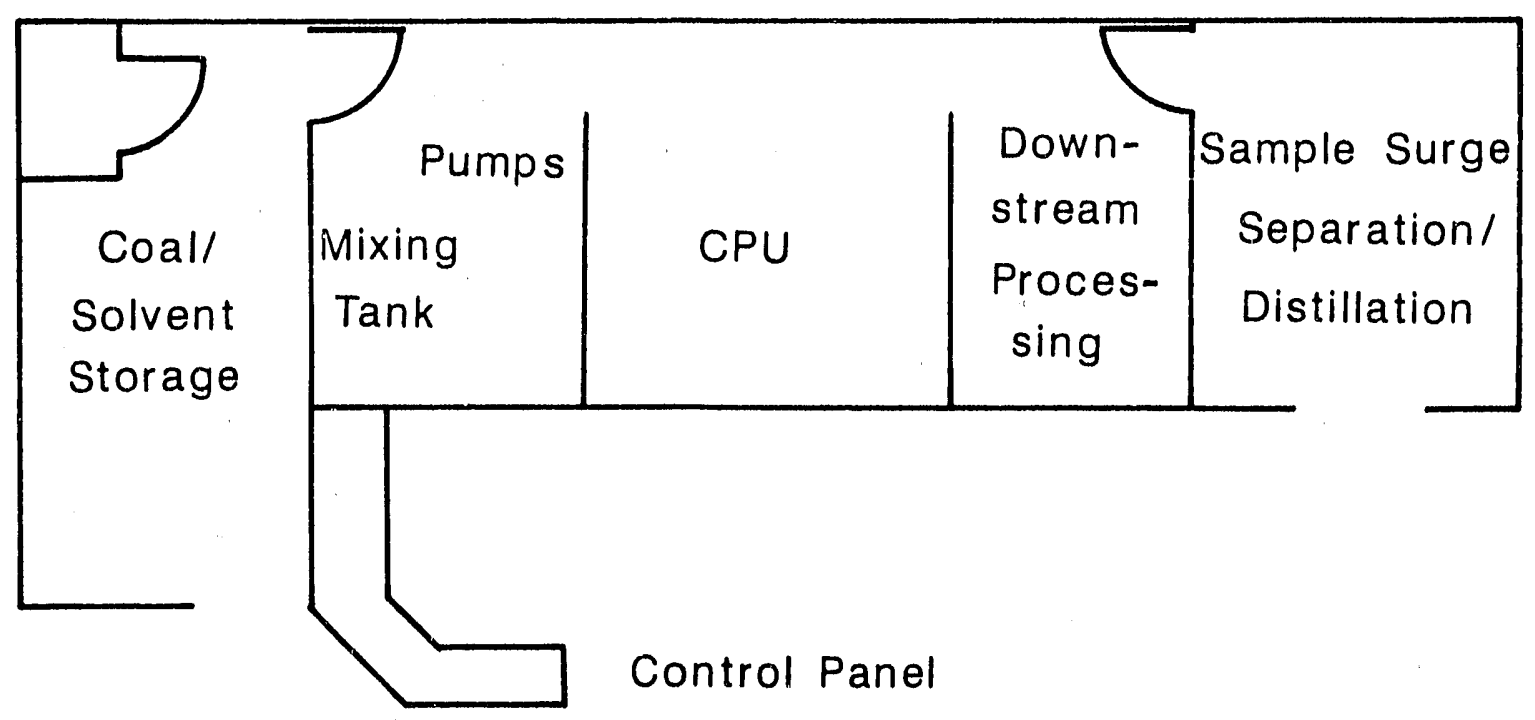

\section{AFTER}

Figure 2. Layout of CPU operations area before and after the refit. 


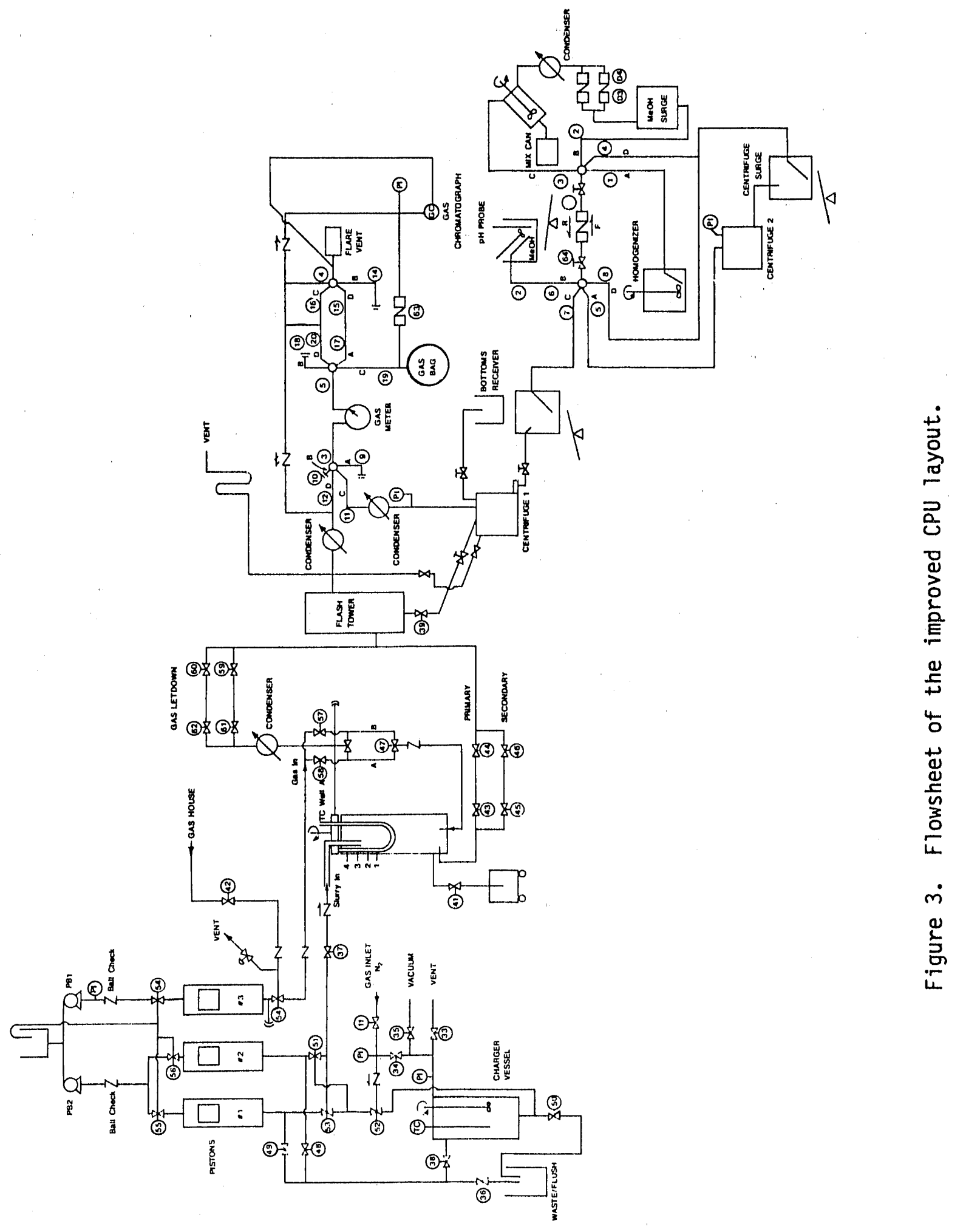


To facilitate easier solvent recovery, a moderately large distillation system was installed in the downstream processing area. The system will permit tracking of solvent and, by recovering methanol to the fullest extent possible, will allow all phenolics and methanol to be recycled. These features make the system very cost-efficient and environmentally sound. The system consists of a 6-inch diameter $\times 9$-foot glass column capable of operation under a full vacuum and at reboiler temperatures of $204^{\circ} \mathrm{C}$. The column has a 5-foot long, fully packed (with York mesh) section with two inlets: one in the upper region and the other in the lower region. A fiowsheet of the system is shown in Figure 4.

\subsubsection{CPU Operation}

Following reconstruction of the CPU, isolated subsystems underwent shakedown testing. The initial operation of the CPU was performed with water.

Six ChemCoal shakedown runs were performed during the last quarter of FY 87/88. Run conditions for these run are presented in Table 6 . The first Chemcoal shakedown run was performed to verify reactor operability with respect to the new system design. Operationally the run was completely successful.

TABLE 6

NOMINAL CPU CHEMCOAL. RUN CONDITIONS

\begin{tabular}{ll}
\hline Temperature & $335^{\circ} \mathrm{C}$ \\
Pressure & $1800 \mathrm{psi}$ \\
Residence time & 30 to 90 minutes \\
Flow Rates: & \\
Gas & $15 \mathrm{scfh} \pm 0.1 \mathrm{cf}$ \\
Liquid & $51 \mathrm{~b} / \mathrm{h} \pm 0.1 \mathrm{~b}$ for 30 -minute run \\
& $2.5 \mathrm{bb} / \mathrm{h} \pm 0.1$ ib for 60 -minute run \\
& $1.25 \mathrm{~b} / \mathrm{h} \pm 0.1$ ib for 90 -minute run \\
\end{tabular}

The second and third ChemCoal runs were performed to produce ChemCoal product to set up the automation sequence in the downstream processing area and to verify reactor level control. The level controller did not work satisfactorily during the tests, and a new level controller was fabricated and installed. During the three ChemCoal runs which followed, the new level controller appeared to work well. The runs were successful as reactor fouling was not evident at the end of the runs.

During the performance of the CPU runs, the reactor level control was not considered accurate enough to invest a good deal of analytical or engineering effort in the determination of yield structures or product quality. However, preliminary measurements indicated that mass balances greater than $99 \%$ and THF conversions of $60 \%-99 \%$ could be attained. 


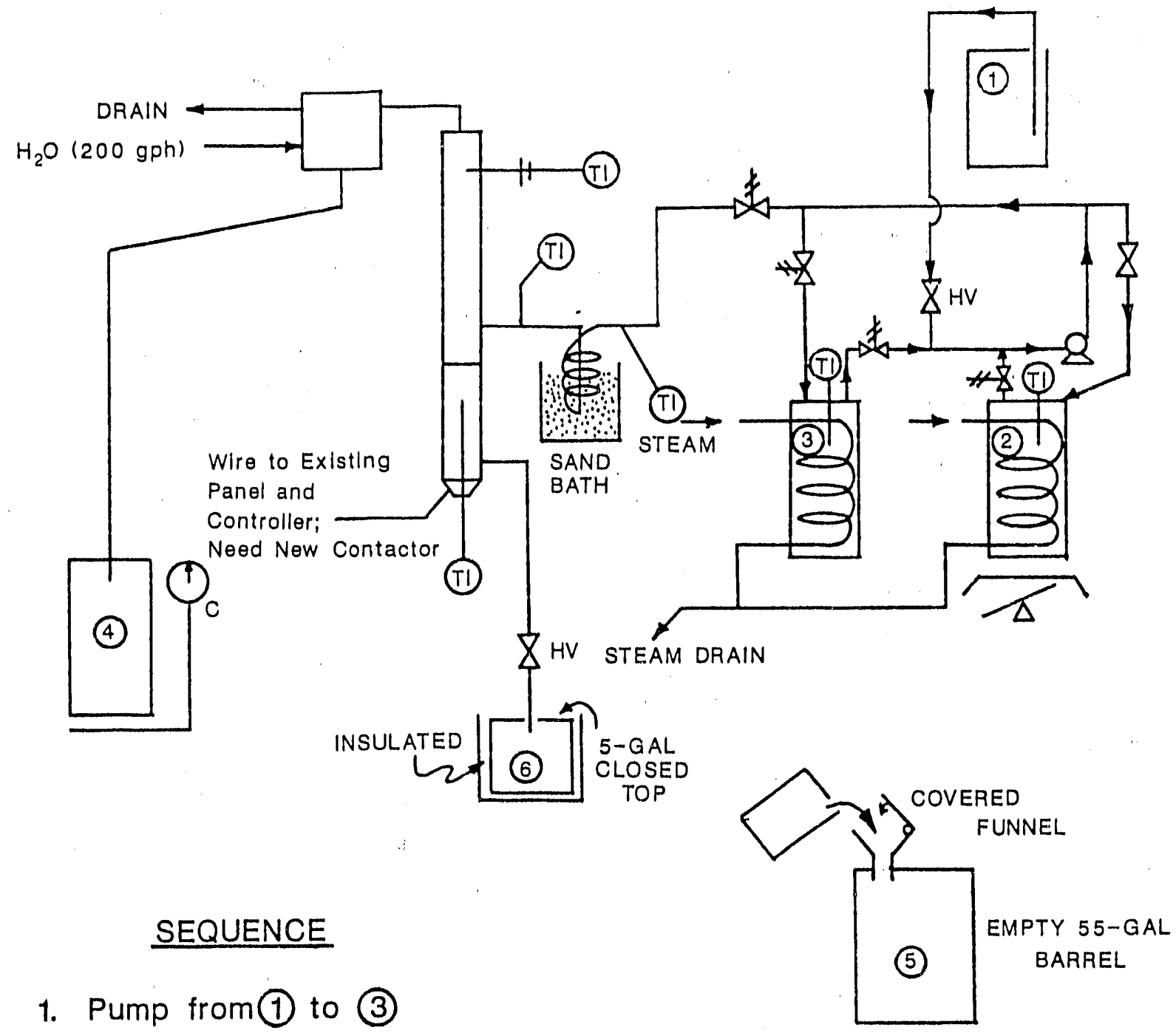

1. Pump from (1) to (3)

2. Warm to temp. in (3), transfer to (2)

3. Operate distillation tower

4. Condensate to (4)

5. Bottoms to (6)

6. Pump from (6) to (5)

7. Rate is by ratio of $A / C$

Figure 4. Flowsheet of new CPU ChemCoal distillation system. 


\subsubsection{Utilization Testing}

A sample of Chemcoal was prepared in the autoclave system for end-use testing as a turbine fuel. This testing will be performed at no cost to the EMRC contract by Allison Gas Turbine Division of General Motors. The ChemCoal sample was extremely low in ash content due to an acidification step which was used. To clean the ChemCoa1, an acidification step was required. During this step, acetic acid, water, and methanol were added to the filtrate. The ratio of water to methanol to filtrate was 2:2:1. Three different samples were prepared using different quantities of acid, based upon the molar quantities of sodium present in the filtrate. It was assumed that all sodium added as $\mathrm{NaOH}$ was present in the filtrate. Samples of the product were then ashed and analyzed. The results of the analyses performed on this sample are presented in Table 7, where they are compared with Allison's target fuel specifications. Ash reduction, which has not been optimized for the Chemcoal Process, is the only target specification not achieved for this batch of ChemCoal solid. In all other aspects (heteroatoms and heating values), the ChemCod solid appears to be superior to the best product deep coal cleaning can obtain.

\section{TABLE 7}

COMPARISON OF UMDEMRC CHEMCOAL WITH ALLISON'S TARGET

FUEL SPECIFICATIONS FOR BENCH-SCALE COMBUSTOR TESTING

\begin{tabular}{lcr}
\hline & $\begin{array}{c}\text { Specifications for } \\
\text { Micronized Coal } \\
\text { Surface Dry }\end{array}$ & $\begin{array}{r}\text { EMRC-Produced } \\
\text { ChemCoal }\end{array}$ \\
\cline { 2 - 3 } Moisture & 3.00 & 3.00 \\
Volatiles & 41.80 & 44.00 \\
Fixed Carbon & 55.00 & 52.50 \\
Ash & $0.20^{\mathrm{a}}$ & 0.50 \\
$\quad$ Total & 100.00 & 100.00 \\
Ultimate Analysis (wt\%) & & \\
Ash & & 0.48 \\
Sulfur & 0.20 & 0.48 \\
Hydrogen & 0.60 & 6.17 \\
Carbon & 5.00 & 0.76 \\
Nitrogen & 75.00 & 11.08 \\
Oxygen & 1.60 & 3.00 \\
Moisture & 14.60 & 100.00 \\
$\quad$ Total & 3.00 & \\
Heating Value (Btu/1b) & 100.00 & 14,800 \\
\hline Higher Heating Value & & \\
\hline
\end{tabular}

a Allison's particle size distribution specification: 3-5 micron mass mean diameter, 15 micron top size. 
The sample was analyzed by SEM and Coulter counter for product size distribution and was found to have a mean particle size of 12-15 $\mu \mathrm{m}$. Figures 5 through 9 are photographs which compare the feed coal and the ChemCoal product. The figures clearly show that the particle size distribution is affected by the processing, resulting in a smaller mean particle size. This is due to the formation of floccules of product which are seen most easily in Figures 8 and 9.

Sole-source justification was begun for the selection of SRI to perform the diesel end-use testing on the ChemCoal product. Twenty-five pounds of product will be produced and sent as soon as the contract is signed. Production of this ChemCoal has begun.

\subsubsection{Economic Study}

The planned in-house economic study of the effects of the process improvements which were made during the refit will be performed during FY $88 / 89$. The delays in the CPU refit resulted in a lack of data necessary for this study. This effort will be improved significantly if funding is made available to enable a PETC-contract A\&E firm to participate in this task with EMRC scientists.
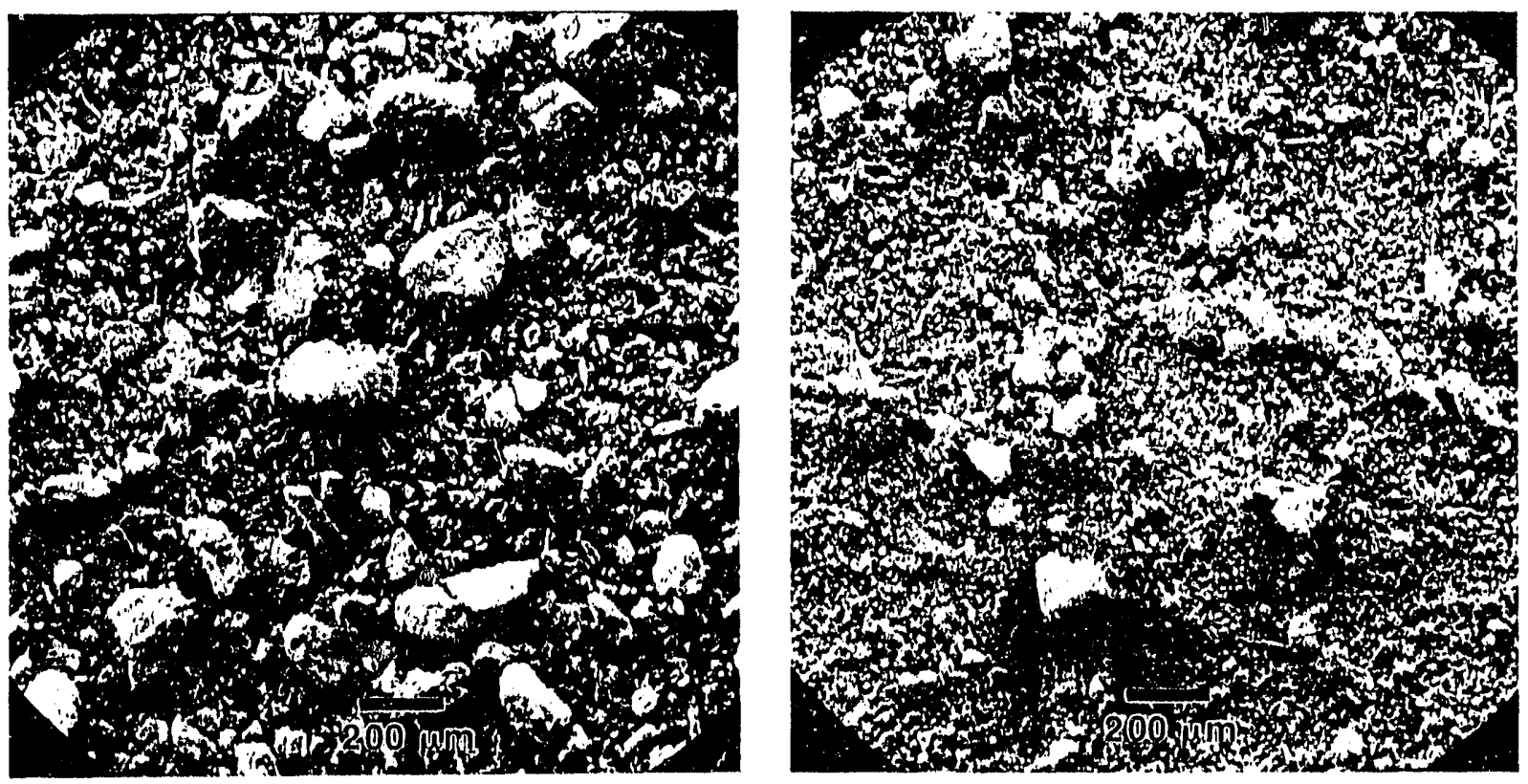

Figure 5. Feed coal (a) and ChemCoal product (b) - Magnification $=50 x$. 

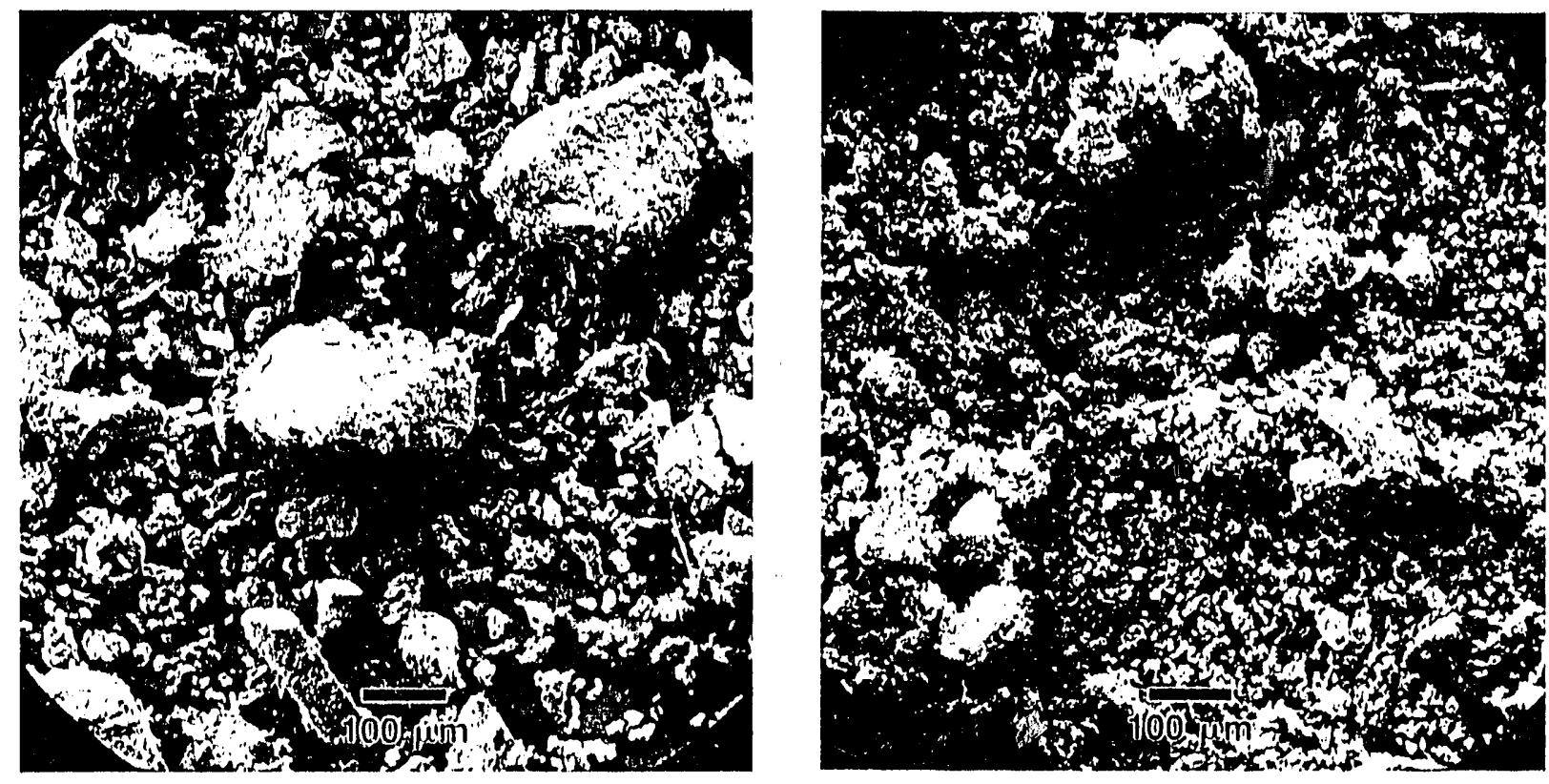

Figure 6. Feed coal (a) and ChemCoal product (b) - Magnification $=100 x$.
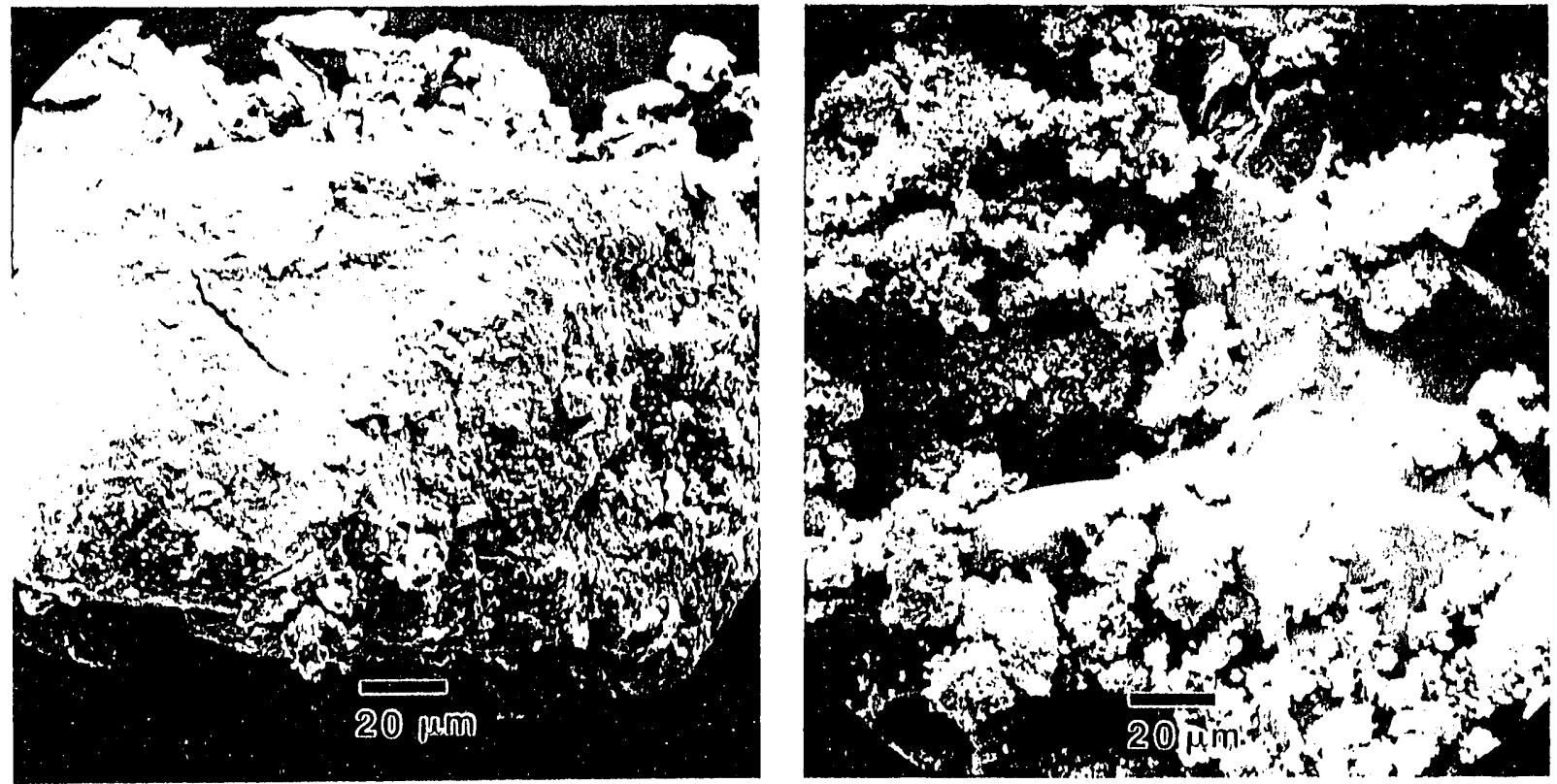

Figure 7. Feed coal (a) and ChemCoal product (b) - Magnification $=500 \mathrm{x}$. 

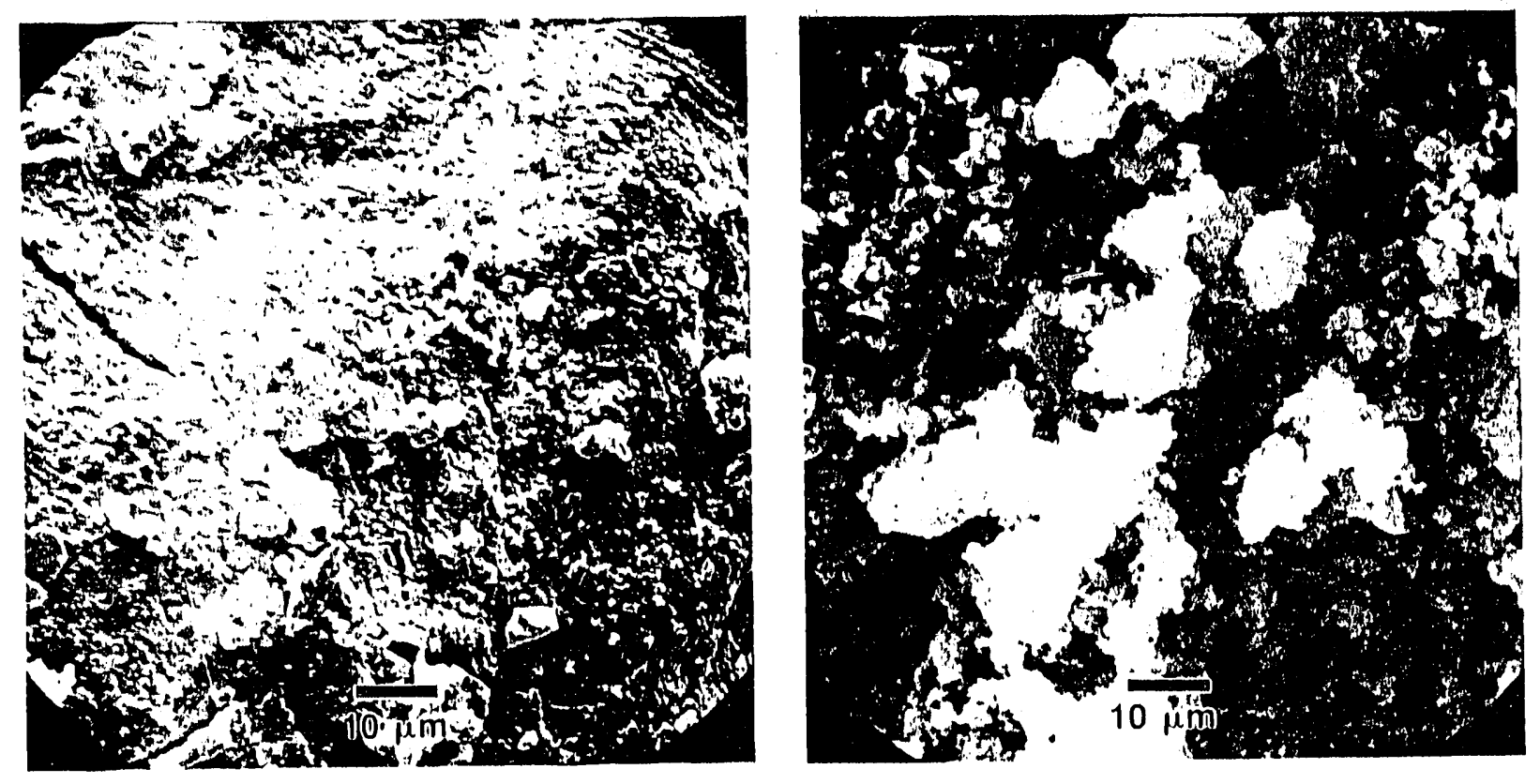

Figure 8. Feed coal (a) and Chemcoal product (b) - Magnification $=1000 x$.

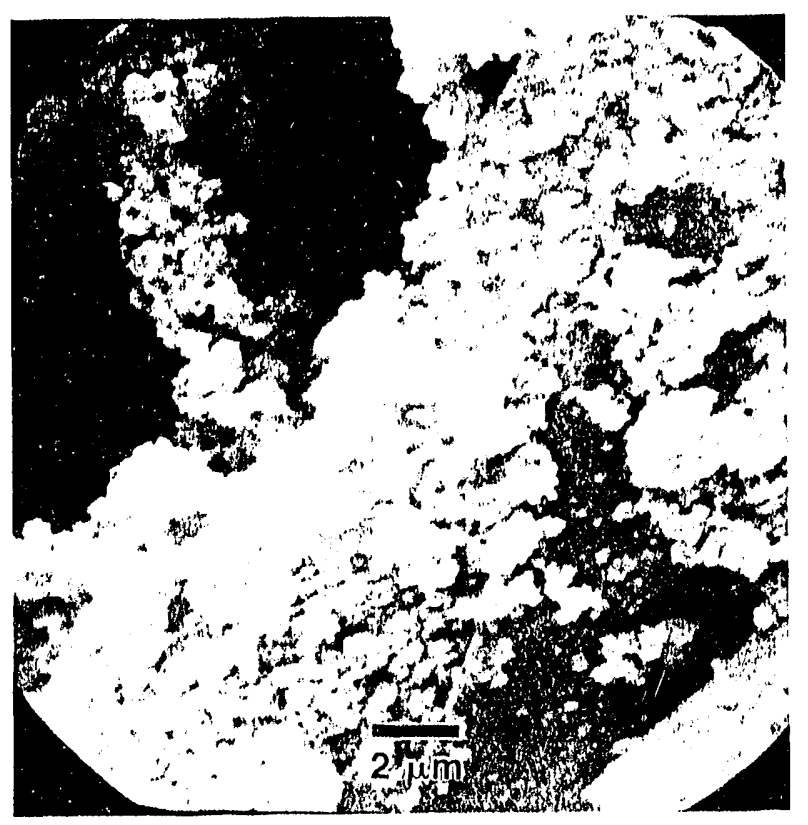

Figure 9. ChemCoal product - Magnification $=5000 x$. 


\subsubsection{Conclusions and Recommendations}

The new reactor and downstream processing designs appear to have had the desired effects of shortening reactor residence times and producing ChemCoal product on line. The computer-controlled system accurately controls all liquid and gas flow rates and has resulted in a reduction in the number of personnel required for CPU operation. The new CPU layout has resulted in a significant decrease in odors in the work area. Shakedown testing of the system has been operationally successful.

\subsection{Results of Task 2 - Agglomeration Studies}

Agglomeration studies of subbituminous coal and lignite have not been as successful as those of bituminous coal because of their greater oxygen content and the hydrophilic nature of their surfaces (1). The focus of this study was to reduce the ash contents of both bituminous coal and lignite, and to determine the effects of particle size, mixing conditions, and oil characteristics on the agglomerates.

The degree to which a coal can be beneficiated by agglomeration is limited by the particle size of the coal. The finer the grinding, the better the chances of liberation of coal-like matter from the associated minerals and increase in recovery of cleaner agglomerates (2).

The type of agglomerating oil used also affects the agglomeration of different coal types. Light agglomerating oils with densities below approximately $0.90 \mathrm{~g} / \mathrm{cc}$ often produce ash reductions that are within $10 \%$ to $20 \%$ of the ash reductions obtained using the Stoddard solvent. The Stoddard solvent is a highly paraffinic reference oil which generally prodices good ash reductions (1). These light oils ar not able to wet the lower-rank coals. If heavier oils (such as coke oven tars, pitches, and petroleum crudes) are used, distinct agglomerates are formed with the low-rank coals (1).

Agglomerated size is affected by system process variables such as mixing speed, mixing time, agitator design, and solvent-to-coal ratio. The size of agglomerated products decreases with an increase in mixing speed and/or an increase in mixing time because of increased impact forces (3). Thorough agitation substantially increases the yield but not necessarily the size of agglomerates, particularly at lower solvent-to-coal ratios (4). If an increase in agglomerate size is desired, the amount of binding oil used, often $15 \%$ to $30 \%$ by weight of coal, is also increased (5).

The $\mathrm{pH}$ of the coal-oil-water slurry affects the removal of pyritic sulfur, the removal of ash, and the amount of time required for agglomeration. The removal of pyritic sulfur is best done at a pH of between 7 and 11 (6). An alkaline solution within this $\mathrm{pH}$ range causes the surface of the pyritic sulfur to become more hydrophilic. The percent ash reduction "may be increased and the time required for agglomeration decreased by a change in the $\mathrm{pH}$ of the coal-oil-water slurry toward the coal's isoelectric point (7). 
The recovery of binding oils would make the oil agglomeration of coals a more economical process. Recovery of $40 \%$ to $50 \%$ of the binding oil by thermal treatment under reduced pressure or with superheated steam maintains the calorific value of the product, increases mechanical stability, decreases moisture content, and generates a product that is free of self-ignition hazards (8).

\subsubsection{Materials and Equipment}

Sma11- and large-scale agglomeration tests were carried out using three different coal types and two different particle sizes. The coal types consisted of as-received Illinois \#6 bituminous coal, as-received Indian Head lignite, and hot-water-dried Indian Head lignite. Particle sizes tested were $70 \mathrm{wt} \%-200$ mesh $(75 \mu \mathrm{m})$ and -325 mesh $(45 \mu \mathrm{m})$. Percent ash values on a moisture-free basis were $12.75 \%, 24.85 \%, 14.63 \%$, and $11.03 \%$ for 70 wt\% -200 mesh bituminous coal, -325 mesh bituminous coal, and -325 mesh lignite, asreceived and hot-water-dried, respectively.

To determine the most suitable binding oil for agglomeration of the coal types, screening tests were performed using nine different liquids. Binding oils which were tested included Arabian resid, 1-octanol, JP-4 aviation fuel, Lummus solvent, Mandan Decant oil, Mayan Crude oil, North Slope ATB, p-xylene, and Great Plains Gasification Plant rectisol naphtha.

Small samples of coal, oil, and water were mixed using a microagglomeration cell to find the most suitable mixtures for use in the larger experiments. A typical analysis used $0.50 \mathrm{~g}$ coal, 0.15 to $0.35 \mathrm{~g}$ oil, and $10 \mathrm{~g}$ water. The stirrer speed ranged from 10,000 to $21,000 \mathrm{rpm}$. Bituminous coal and water were mixed with Mandan Decant oil or mixtures of Mandan Decant oil and either p-xylene or rectisol naphtha to find the optimum solvent-tocoal weight ratio.

The equipment used to carry out the large-scale experiments consisted of a variable-speed blender with a fabricated stirring rod, a balance for weighing coal and oil feedstocks, and a 100 mesh $(150 \mu \mathrm{m})$ screen for separating the agglomeration products.

\subsubsection{Results of Testing}

Microagglomeration and large-scale experiments produced agglomerates which varied in size and texture with different solvent-to-coal ratios, mixing speeds, and mixing times. The final agglomerates have been classified into three different forms. Microagglomerates, or flocs as they are sometimes called, are the smallest. Discrete agglomerates are medium sized, and amalgams are large coal-in-oil pastes. Agglomerate texture was classified as either firm or loose. The formation of discrete agglomerates firm in texture was preferred. Figures 10 and 11 are photographs of discrete and amaigan agglomerates, respectively, formed from $70 \mathrm{wt} \%-200$ mesh bituminous coal and a 50 wt\% mixture of Mandan Decant $0 i l$ and $p-x y l e n e$ binding oil. 


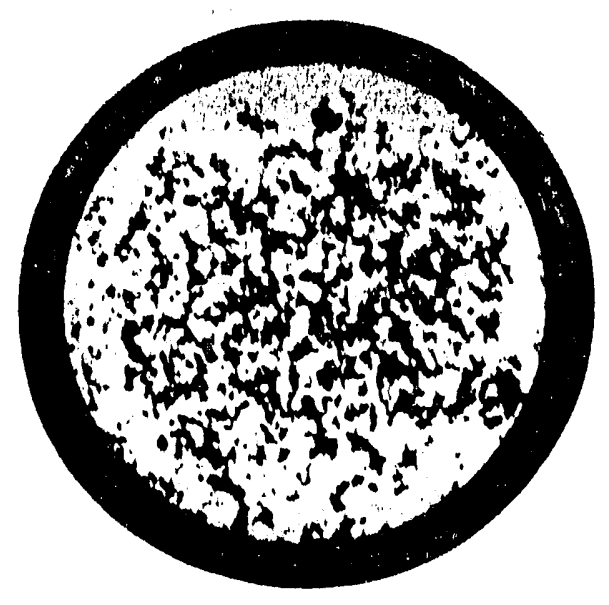

Figure 10. Discrete agglomerates formed from -200 mesh, as-received Illinois \#6 bituminous coal and 50 wt\% Mandan Decant $0 i 1$ in p-xylene binding oil.

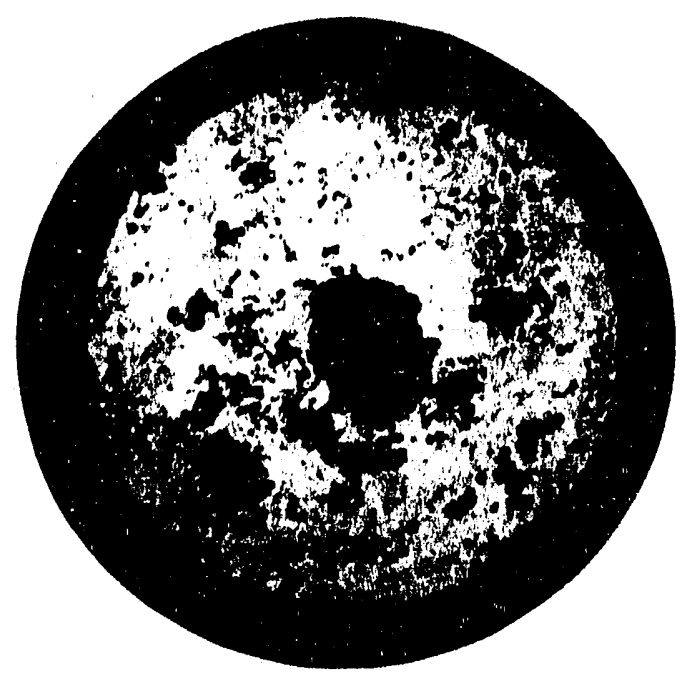

Figure 11. Amalgam agglomerate formed from -200 mesh, as-received Illinois \#6 bituminous coal and 50 wt\% Mandan Decant $0 i 1$ in $p$-xylene binding oil. 
The microagglomeration experiments provided the solvent-to-coal ratios needed to produce stable agglomerates in the large-scale experiments. Tables 8 and 9 give the oil type, solvent-to-coal ratio, mixing speed, mixing time, and agglomerate type for the experiments performed using $70 \mathrm{wt} \%-200$ mesh and -325 mesh bituminous coal. From the results given in these tab?es, it can be seen that the Mandan Decant oil alone acts slowly as a binder. For this reason, a mixture of Mandan Decant 011 in p-xylene was tried. Sun and McMorris found that binding oils of medium density are required to obtain satisfactory recovery levels for the coal fines (1). A $50 \mathrm{wt} \%$ solution of the two oils has a specific gravity of 0.9400 , classifying the mixture as a medium-density 0i1. The results show that a $50 \mathrm{wt} \%$ mixture of the Mandan Decant 011 agglomerated the -325 mesh bituminous coal within minutes; however, a sample of -325 mesh bituminous coal combined with a $50 \mathrm{wt} \%$ Mandan Decant oil and $p$-xylene mixture in a solvent-to-coal ratio of 0.8 did not form agglomerates.

TABLE 8

MICROAGGLOMERATION RESULTS FOR - 325 MESH

ILLINOIS \#6 BITUMINOUS COAL, AS RECEIVED

\begin{tabular}{|c|c|c|c|c|c|c|c|}
\hline & Binding & Solvent/Coa 1 & Mix Speed & Mix Time & $(\min )$ & \multicolumn{2}{|c|}{ Agglomerates } \\
\hline Run \# & $0 i 1$ & Ratio & (rpm) & $0 \mathrm{il}-\mathrm{H}_{2} \mathrm{O}$ & Slurry & Type & Texture \\
\hline 1 & $M D^{\mathrm{a}}$ & 0.4 & 10,000 & 1 & 3 & floc & loose \\
\hline 2 & MD & 0.5 & 10,000 & 1 & 3 & floc & loose \\
\hline 3 & MD & 0.6 & 10,000 & 1 & 3 & amalgam & firm \\
\hline 4 & MD & 0.7 & 10,000 & 1 & 3 & discrete & loose \\
\hline 5 & $50 \% M D / X Y^{b}$ & 0.5 & 10,000 & 1 & 3 & discrete & firm \\
\hline 6 & $50 \% \mathrm{MD} / \mathrm{XY}$ & 0.6 & 10,000 & 1 & 3 & discrete & firm \\
\hline 7 & $50 \% M D / X Y$ & 0.7 & 10,000 & 1 & 3 & amalgam & firm \\
\hline 8 & $50 \% \mathrm{MD} / \mathrm{XY}$ & 0.8 & 10,000 & 1 & 3 & amalgam & firm \\
\hline 9 & $50 \% \mathrm{MD} / \mathrm{XY}$ & 0.5 & 10,000 & 2 & 3 & amalgam & firm \\
\hline 10 & $50 \% \mathrm{MD} / \mathrm{XY}$ & 0.6 & 10,000 & 2 & 3 & amalgam & firm \\
\hline 11 & $50 \% M D / X Y$ & 0.7 & 10,000 & 2 & 3 & amalgam & firm \\
\hline 12 & $50 \% M D / X Y$ & 0.8 & 10,000 & 1 & 1 & no agglom & rate \\
\hline
\end{tabular}

a Mandan Decant oi1

b 50 wt\% Mandan Decant oil in p-xylene 
TABLE 9

MICROAGGLOMERATION RESULTS FOR 70 WT\% -200 MESH ILLINOIS \#6 BITJMINOUS COAL, AS RECEIVED

\begin{tabular}{|c|c|c|c|c|c|c|c|}
\hline \multirow[b]{2}{*}{ Run \# } & \multirow{2}{*}{$\begin{array}{c}\text { Binding } \\
0 i 1\end{array}$} & \multirow{2}{*}{$\begin{array}{l}\text { Solvent/CoaT } \\
\text { Ratio }\end{array}$} & \multirow{2}{*}{$\begin{array}{l}\text { Mix Speed } \\
(\mathrm{rpm})\end{array}$} & \multirow{2}{*}{ 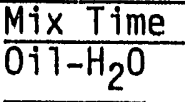 } & \multirow{2}{*}{$\frac{(\min )}{\text { Siurry }}$} & \multicolumn{2}{|c|}{ Agglomerates } \\
\hline & & & & & & Type & Texture \\
\hline 1 & $50 \% M D / X Y^{a}$ & 0.6 & 20,000 & 1 & 3 & ama lgam & firm \\
\hline 2 & $50 \% M D / X Y$ & 0.7 & 20,000 & 1 & 3 & ama lgam & firm \\
\hline 3 & $50 \% \mathrm{MD} / \mathrm{XY}$ & 0.5 & 10,000 & 2 & 3 & amalgam & firm \\
\hline 4 & 50:MD/XY & 0.6 & 10,000 & 2 & 3 & amalgam & firm \\
\hline 5 & $50 \% \mathrm{MD} / \mathrm{XY}$ & 0.7 & 10,000 & 2 & 3 & amalgam & firm \\
\hline
\end{tabular}

a 50 wt\% Mandan Decant $0 i 1$ in p-xylene

Before performing additional large-scale experiments, the solvent-to-coal ratios which formed discrete agglomerates when tested with the microagglomerator were reviewed and solvent-to-coal ratios below or equal to 0.5 were used.

Results of the large-scale experiments using $50 \mathrm{wt} \%$ Mandan Decant oil in p-xylene binding oil and bituminous coal at solvent-to-coal ratios of 0.25 to 0.50 are listed in Table 10. The 011 was dispersed in the water phase before adding the coal to aid in the surface wetting of the particles. Propeller speeds of 7500 to $10,500 \mathrm{rpm}$ (tip speeds of 25 to 35 meters per second) and mixing times of 3 to 6 minutes were used. These conditions have been used by the Convertol and 01 if loc processes in Germany (1). By contrast, slower tip speeds and longer mixing periods could have been used.

The data from Table 10 were plotted to show the effects of mixing speed, mixing time, and particle size on the agglomerate ash content. Figures 12 and 13 show that the 6-minute mixing period consistently reduced ash content at each mixing speed as the solvent-to-coal ratio was increased. The 3-minute mixing period only produced fluctuations in the percent product ash at mixing speeds of $13,000 \mathrm{rpm}$. This may indicate that the 3-minute mixing period was not long enough and the mixing speed too slow for the binding oil to completely wet the coal particles.

Figures 14 and 15 show the amount of ash contained in the product after mixing times of 3 and 6 minutes, respectively. At the 3 -minute mixing time, a mix speed of $13,000 \mathrm{rpm}$ exhibited fluctuations in the ash reduction as the solvent-to-coal ratio increased. However, at the 6-minute mixing period, both blender speeds consistently reduced ash content. The mix speed of $16,000 \mathrm{rpm}$ resulted in a percent product ash that was $1 \%$ to $2 \%$ lower than that obtained at the $13,000 \mathrm{rpm}$ mix speed. 
TABLE 10

AGGLOMERATION RESULTS FOR A 50 WT\% MANDAN DECANT OIL

IN P-XYLENE AND 70 WT\% - 200 MESH

ILLINOIS \#6 BITUMINOUS COAL, AS RECEIVED

\begin{tabular}{|c|c|c|c|c|c|c|c|c|}
\hline Run \# & $\begin{array}{c}\text { Sol/Coal } \\
\text { Ratio }\end{array}$ & $\begin{array}{l}\text { Mix Speed } \\
(\mathrm{rpm})\end{array}$ & $\frac{\text { Mix Time }}{\mathrm{Oil}-\mathrm{H}_{2} \mathrm{O}}$ & $\frac{(\min )}{\text { siurry }}$ & $\frac{\text { Agglom }}{\text { Type }}$ & $\frac{\text { erates }}{\text { Texture }}$ & $\mathrm{pH}$ & $\begin{array}{c}\text { Product } \\
\text { Ash }\end{array}$ \\
\hline 1 & 0.25 & 13,000 & 2 & 3 & discrete & firm & $-a$ & $11.76^{b}$ \\
\hline 2 & 0.30 & 13,000 & 2 & 3 & discrete & firm & - & 11.75 \\
\hline 3 & 0.35 & 13,000 & 2 & 3 & discrete & firm & - & 10.91 \\
\hline 4 & 0.40 & 13,000 & 2 & 3 & ama lgam & loose & - & 11.05 \\
\hline 5 & 0.50 & 13,000 & 2 & 3 & ama lgam & firm & - & 11.31 \\
\hline 6 & 0.25 & 16,000 & 2 & 3 & discrete & firm & 6 & 11.82 \\
\hline 7 & 0.30 & 16,000 & 2 & 3 & discrete & firm & 6 & 11.55 \\
\hline 8 & 0.35 & 16,000 & 2 & 3 & discrete & firm & 6 & 11.38 \\
\hline 9 & 0.25 & 13,000 & 2 & 6 & discrete & firm & - & 11.97 \\
\hline 10 & 0.30 & 13,000 & 2 & 6 & ama lgam & firm & - & 11.69 \\
\hline 11 & 0.35 & 13,000 & 2 & 6 & ama lgam & firm & - & 11.37 \\
\hline 12 & 0.25 & 16,000 & 2 & 6 & discrete & firm & - & 11.25 \\
\hline 13 & 0.30 & 16,000 & 2 & 6 & discrete & firm & - & 11.07 \\
\hline 14 & 0.35 & 16,000 & 2 & 6 & discrete & firm & - & 10.96 \\
\hline $15^{\mathrm{C}}$ & 0.25 & 16,000 & 2 & 6 & floc & firm & - & 21.83 \\
\hline $16^{c}$ & 0.30 & 16,000 & 2 & 6 & floc & firm & - & 20.99 \\
\hline $17^{c}$ & 0.35 & 16,000 & 2 & 6 & discrete & firm & - & 20.55 \\
\hline
\end{tabular}

a $\mathrm{pH}$ was not taken.

b Moisture-free basis.

C Illinois \#6 bituminous coa 1, -325 mesh particles, as received. Ash content of 70 wt\% -200 mesh coal was $12.75 \%$, and $24.85 \%$ for -325 mesh coal, moisture-free basis. 


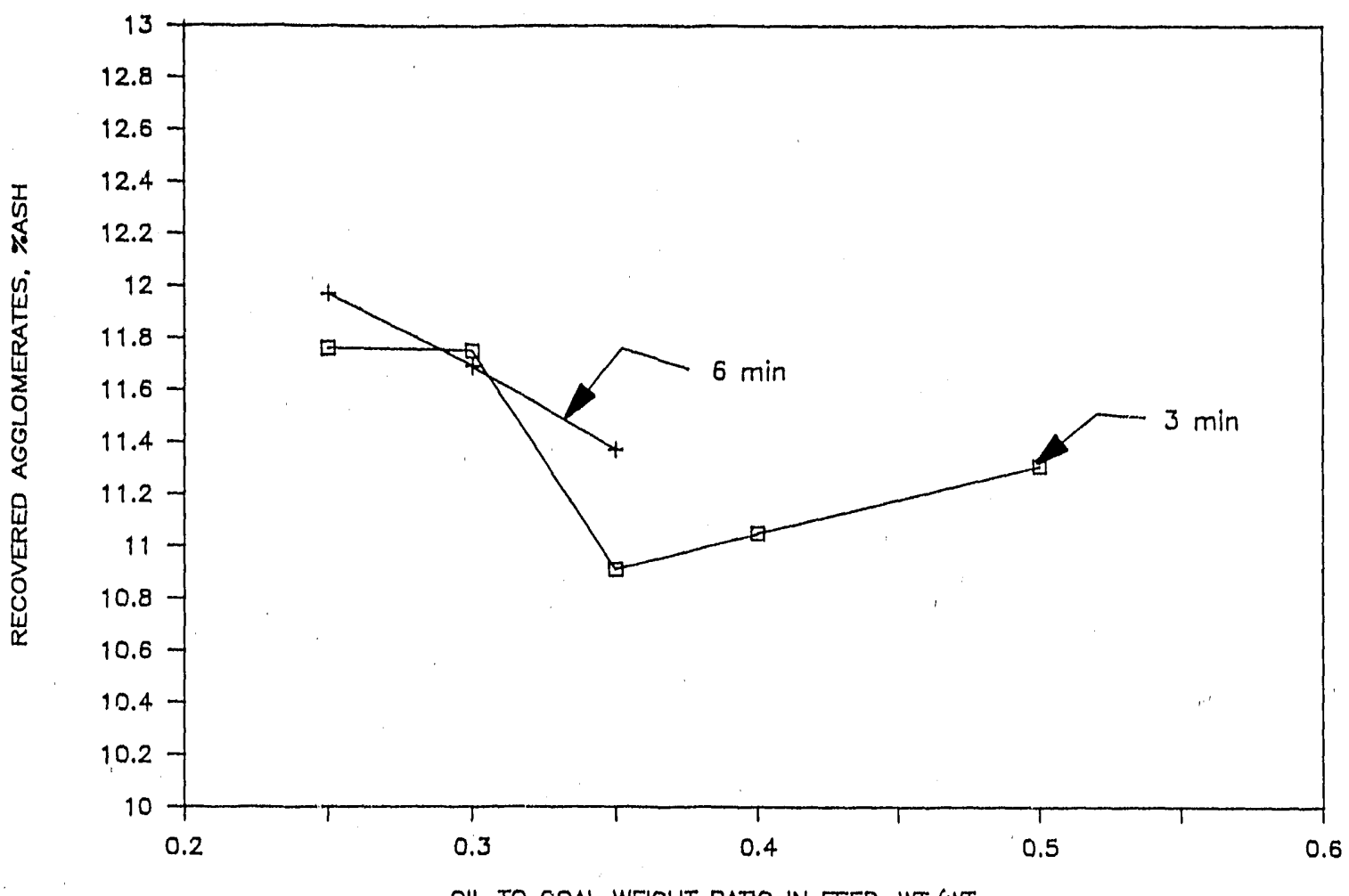

Figure 12. Percent agglomerate ash (moisture-free basis) as a function of solvent-to-coal ratio for 3- and 6-minute mixing periods. Mandan Decant $0 i 1$ in $p-x y l e n e$ binder and bituminous coal were

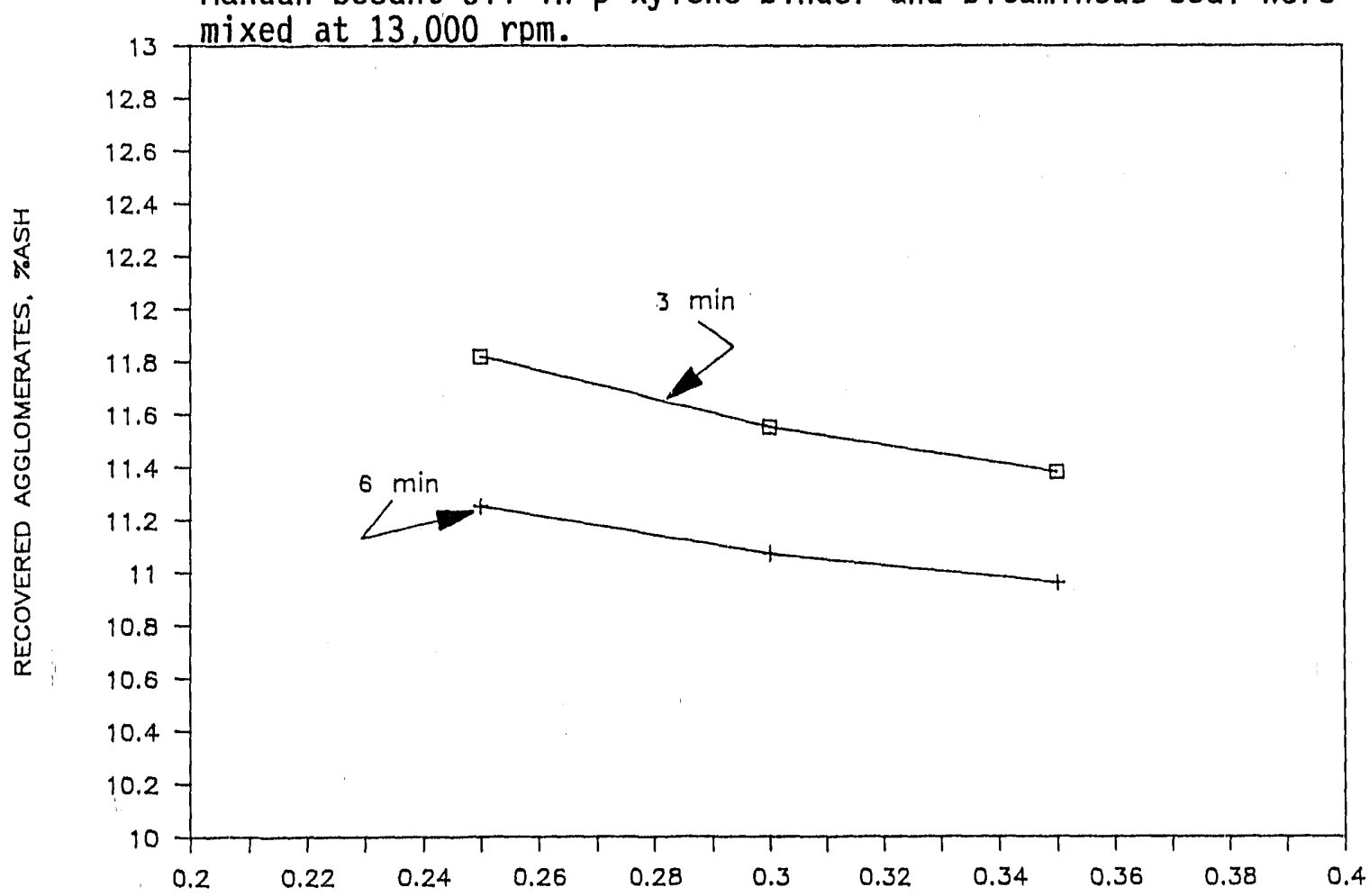

Figure 13. Percent agglomerate ash (moisture-free basis) as a function of solvent-to-coal ratio for 3- and 6-minute mixing periods. Mandan Decant $0 i l$ in $p-x y l e n e$ binder and bituminous coal were mixed at $16,000 \mathrm{rpm}$. 


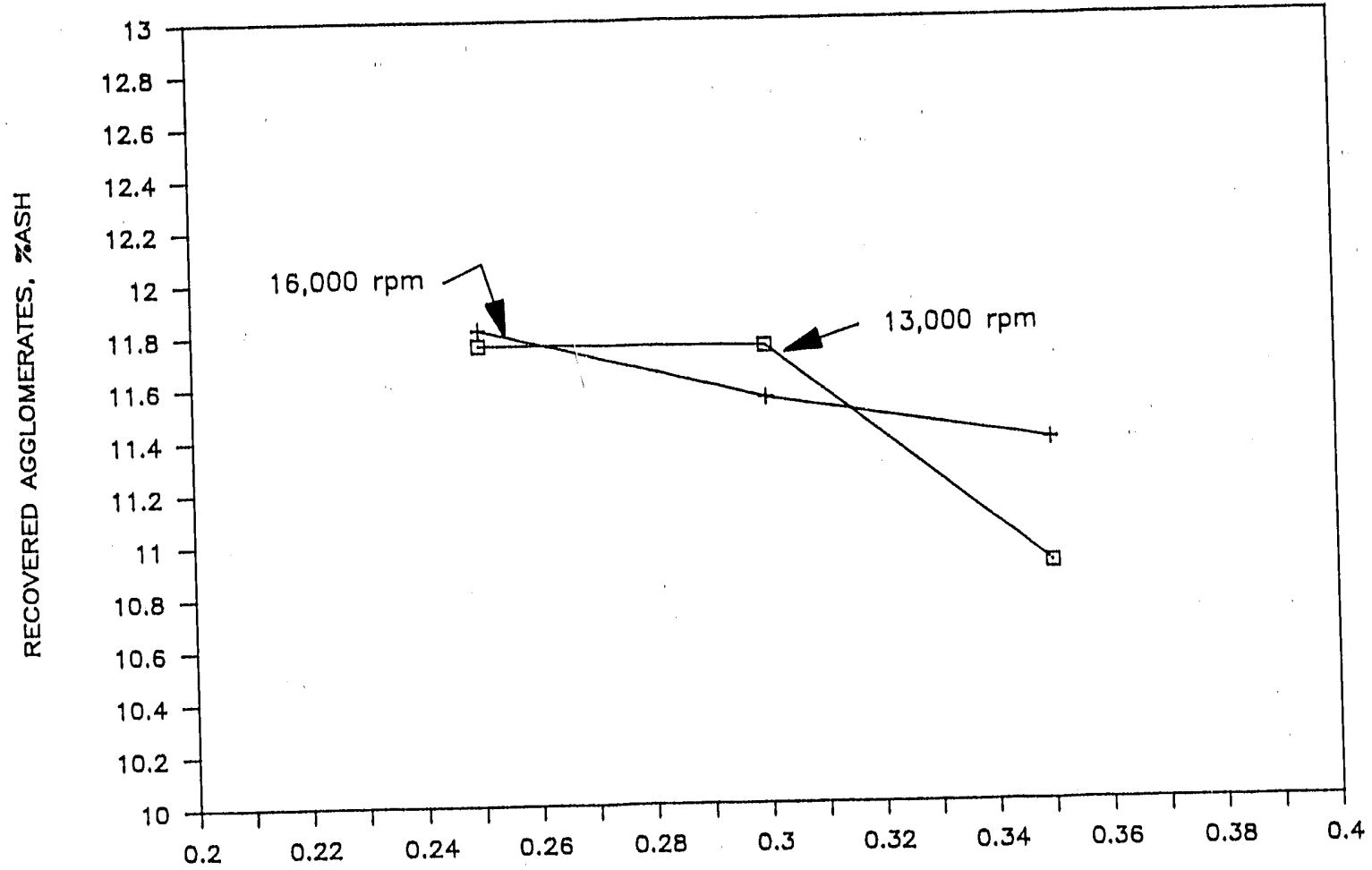

OIL TO COAL WEIGHT RATIO IN FEED. WT/WT

Figure 14. Percent agglomerate ash (moisture-free basis) as a function of solvent-to-coal ratio for mixing speeds of 13,000 and $16,000 \mathrm{rpm}$. Mandan Decant $0 \mathrm{il}$ in $\mathrm{p}$-xylene binder and bituminous coal were mixed for 3 minutes.

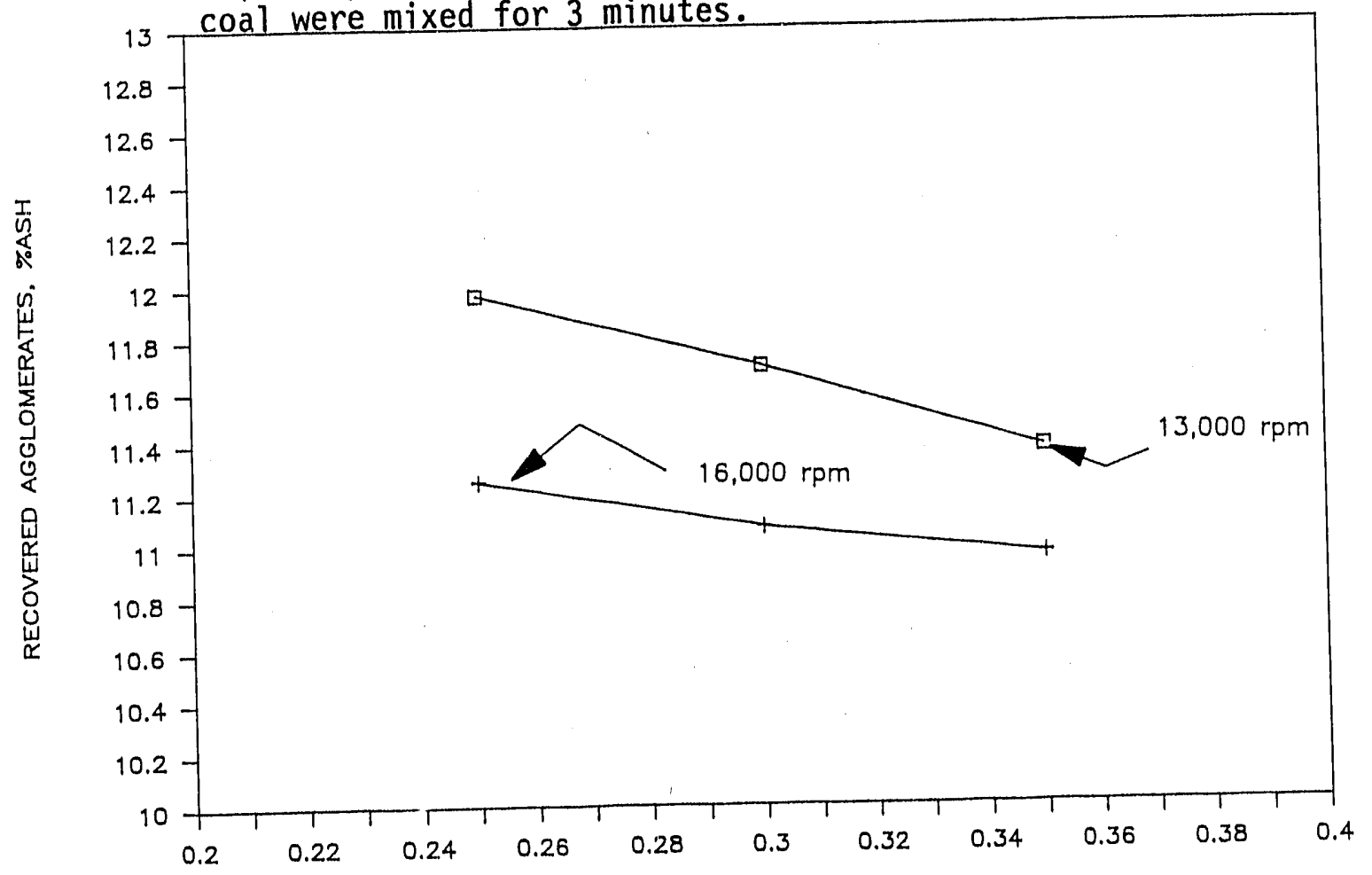

OIL TO COAL WEIGHT RATIO IN FEED, WT/WT
Figure 15. Percent agglomerate ash (mO isture-free bas is) as a function of solvent-to-coal ratio for mixing speeds of 13,000 and $16,000 \mathrm{rpm}$. Mandan Decant $0 i 1$ in $\mathrm{p}$-xylene binder and bituminous coal were mixed for 6 minutes. 
Figure 16 presents the percent product ash as a function of solvent-tocoal ratio for 70 wt -200 mesh and -325 mesh Illinois \#6 bituminous coal. These data were taken at a mixing speed of $16,000 \mathrm{rpm}$ for a mixing period of 6 minutes. Although the product ash content of the -325 mesh coal was greater than that of the -200 mesh coal, the ash reduction for the -325 mesh coal was greater. The ash content of the -325 mesh coal, on a dry basis, was $24.85 \%$, while the $70 \mathrm{wt} \%-200$ mesh coal contained $12.75 \%$ ash on the same basis. This difference in ash content may be due to the fact that the samples were obtained from two different mine locations. Coals of finer particle sizes have been found to produce a cleaner product after agglomeration (1). The -325 mesh coal apparently allows more of the ash and mineral matter to be liberated, resulting in a cleaner agglomerate product. The greatest ash reduction for both 70 wt\% -200 mesh and -325 mesh bituminous coal occurred at a blender speed of $16,000 \mathrm{rpm}$ and a mixing time of 6 minutes. Higher ash reductions may require longer mixing times.

Further testing was performed using as-received and hot-water-dried Indian Head lignite. Table 11 lists the results of the microagglomeration of -325 mesh as-received lignite and a mixture of 50 wt\% Mandan Decant oil in p-xylene mixture, while Table 12 lists the results of the microagglomeration of -325 mesh hot-water-dried lignite. The hot-water-dried lignite produced an agglomerate that was more stable at higher mixing speeds.

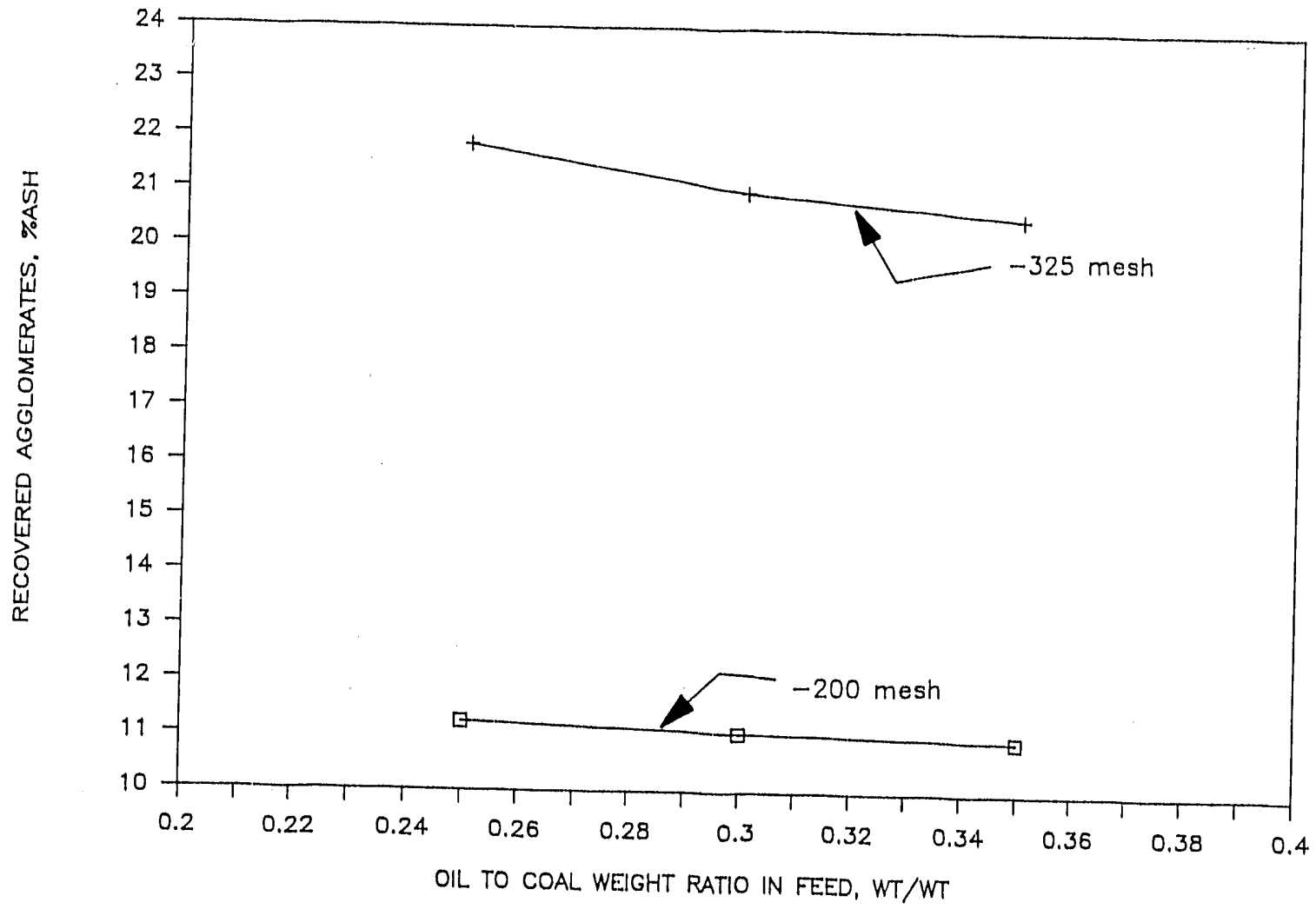

Figure 16. Percent agglomerate ash (moisture-free basis) as a function of solvent-to-coal ratio for both 70 wt $\%-200$ mesh and -325 mesh bituminous coal. Mixing speed was 16,000 rpm for 6 minutes. 
TABLE 11

MICROAGGLOMERATION RESULTS FOR - 325 MESH

INDIAN HEAD LIGNITE, AS RECEIVED

\begin{tabular}{|c|c|c|c|c|c|c|c|}
\hline & \multirow{2}{*}{$\begin{array}{c}\text { Binding } \\
011 \\
\end{array}$} & \multirow{2}{*}{$\begin{array}{c}\text { Solvent/Coal } \\
\text { Ratio }\end{array}$} & \multirow{2}{*}{$\begin{array}{c}\text { Mix Speed } \\
(\mathrm{rpm})\end{array}$} & \multirow{2}{*}{$\frac{\text { Mix Time }}{0 i 1-\mathrm{H}_{2} \mathrm{O}}$} & \multirow{2}{*}{$\frac{(\min )}{\text { STurry }}$} & \multicolumn{2}{|c|}{ Agglomerates } \\
\hline & & & & & & Type & Texture \\
\hline 1 & $50 \% M D / X Y^{2}$ & 0.25 & 10,000 & 2 & 3 & floc & firm \\
\hline 2 & $50 \% M D / X Y$ & 0.30 & 10,000 & 2 & 3 & floc & firm \\
\hline 3 & $50 \% M D / X Y$ & 0.35 & 10,000 & 2 & 3 & floc & firm \\
\hline 4 & $50 \% M D / X Y$ & 0.40 & 10,000 & 2 & 3 & discrete & firm \\
\hline 5 & $50 \% M D / X Y$ & 0.45 & 10,000 & 2 & 3 & discrete & firm \\
\hline 6 & $50 \% M D / X Y$ & 0.50 & 10,000 & 2 & 3 & discrete & firm \\
\hline 7 & $50 \% M D / X Y$ & 0.60 & 10,000 & 2 & 3 & discrete & firm \\
\hline 8 & $50 \% M D / X Y$ & 0.70 & 10,000 & 2 & 3 & discrete & firm \\
\hline
\end{tabular}

50 wt\% Mandan Decant $0 i 1$ in p-xylene binding oil.

TABLE 12

MICROAGGLOMERATION RESULTS FOR -325 MESH

INDIAN HEAD LIGNITE, HOT-WATER DRIED AT $330^{\circ} \mathrm{C}$

\begin{tabular}{|c|c|c|c|c|c|c|c|}
\hline Run \# & $\begin{array}{c}\text { Binding } \\
0 i 1\end{array}$ & $\begin{array}{c}\text { Solvent/Coal } \\
\text { Ratio }\end{array}$ & $\begin{array}{l}\text { Mix Speed } \\
(\mathrm{rpm})\end{array}$ & $\frac{\text { Mix Time }}{0 i 1-\mathrm{H}_{2} \mathrm{O}}$ & & Agg lomer & Cates \\
\hline $\begin{array}{r}1 \\
2 \\
3 \\
4 \\
5 \\
6 \\
7 \\
8 \\
9 \\
10\end{array}$ & $\begin{array}{l}50 \% M D / X Y a \\
50 \% M D / X Y \\
50 \% M D / X Y \\
50 \% M D / X Y \\
50 \% M D / X Y \\
50 \% M D / X Y \\
50 \% M D / X Y \\
50 \% M D / X Y \\
50 \% M D / X Y \\
50 \% M D / X Y\end{array}$ & $\begin{array}{l}0.25 \\
0.30 \\
0.35 \\
0.40 \\
0.50 \\
0.25 \\
0.30 \\
0.35 \\
0.40 \\
0.50\end{array}$ & $\begin{array}{l}10,000 \\
10,000 \\
10,000 \\
10,000 \\
10,000 \\
20,000 \\
20,000 \\
20,000 \\
20,000 \\
20,000\end{array}$ & $\begin{array}{l}2 \\
2 \\
2 \\
2 \\
2 \\
2 \\
2 \\
2 \\
2 \\
2\end{array}$ & $\begin{array}{l}3 \\
3 \\
3 \\
3 \\
3 \\
3 \\
3 \\
3 \\
3 \\
3\end{array}$ & $\begin{array}{l}\text { floc } \\
\text { discrete } \\
\text { discrete } \\
\text { amalgam } \\
\text { amalgam } \\
\text { discrete } \\
\text { discrete } \\
\text { discrete } \\
\text { discrete } \\
\text { amalgam }\end{array}$ & $\begin{array}{l}\text { firm } \\
\text { firm } \\
\text { firm } \\
\text { firm } \\
\text { firm } \\
\text { firm } \\
\text { firm } \\
\text { firm } \\
\text { firm } \\
\text { firm }\end{array}$ \\
\hline
\end{tabular}

a 50 wt\% Mandan Decant oil in p-xylene binding oil. 
Results for the agglomeration experiments using 50 wt\% Mandan Decant oil in $\mathrm{p}-\mathrm{xy}$ lene and -325 mesh lignite at mixing speeds of $10,000 \mathrm{rpm}$ for 3 minutes may be seen in Table 13. It was hoped that lower solvent-to-coal ratios would avoid the formation of amaigams and liberate more of the ash and mineral matter. Figure 17 plots the percent product ash versus solvent-to-coal ratio for -325 mesh, as-received ifgnite and hot-water-dried lignite at a mixing speed of $10,000 \mathrm{rpm}$ for 3 minutes. The hot-water-dried ilgnite consistentiy resulted in product ash contents that were $2 \%$ to $3 \%$ lower than those obtained with the as-received lignite at varying solvent-to-coal ratios, indicating that the hot-water-dried lignite does liberate the ash. Figure 18 compares the effect of mixing speed on agglomeration of the same matertals at the same conditions. As the plot shows, mixing speed produced agglomerates with ash contents $0.4 \%$ to $1.14 \%$ less than mixing speed of $10,000 \mathrm{rpm}$.

Additional experiments using -325 mesh, as-received lignite and two different binding oils, 50 wt\% Mandan Decant ofl in p-xylene and 50 wt\% Mandan Decant 011 in rectisol naphtha, were performed. The results are listed in Table 14. The same solvent-to-coal ratio, mixing speed, and mixing time were used for each run. The Mandan Decant 011 in $p$-xylene binder produced an average product ash content of $12.09 \%$. This value was only slightly lower than the $12.72 \%$ content of the Mandan Decant 011 in rectisol naphtha binder and indicates that rectisol naphtha may be a useful substitute for $p-x y$ lene when mixing low- and high-density oils to give a medium-density binding 011 .

\section{TABLE 13}

AGGLOMERATION RESULTS FOR 50 WT\% MANDAN DECANT OIL IN P-XYLENE AND -325 MESH INDIAN HEAD LIGNITE, HOT-WATER DRIED AT $330^{\circ} \mathrm{C}$

\begin{tabular}{|c|c|c|c|c|c|c|c|c|}
\hline \multirow[b]{2}{*}{ Run \# } & \multirow{2}{*}{$\begin{array}{c}\text { Sol/Coal } \\
\text { Ratio }\end{array}$} & \multirow{2}{*}{$\begin{array}{l}\text { Mix Speed } \\
(\mathrm{rpm})\end{array}$} & \multicolumn{2}{|c|}{ Mix Time (min) } & \multicolumn{2}{|c|}{ Agglomerates } & \multirow[b]{2}{*}{$\mathrm{pH}$} & \multirow{2}{*}{$\begin{array}{c}\% \text { Product } \\
\text { Ash }\end{array}$} \\
\hline & & & $\mathrm{O}+1-\mathrm{H}_{2} \mathrm{O}$ & STurry & Type & Texture & & \\
\hline $1^{a}$ & 0.35 & 10,000 & 2 & 3 & discrete & firm & $-b$ & $12.93^{\mathrm{C}}$ \\
\hline $2^{a}$ & 0.40 & 10,000 & 2 & 3 & discrete & firm & - & 13.38 \\
\hline $3^{a}$ & 0.45 & 10,000 & 2 & 3 & discrete & firm & - & 13.89 \\
\hline 4 & 0.25 & 10,000 & 2 & 3 & ama lgam & firm & - & 8.73 \\
\hline 5 & 0.30 & 10,000 & 2 & 3 & ama lgam & firm & - & 10.29 \\
\hline 6 & 0.3 & 10,000 & 2 & 3 & ama lgam & firm & - & 10.12 \\
\hline 7 & 0.4 & 10,000 & 2 & 3 & ama lgam & firm & - & 10.27 \\
\hline 8 & & & 2 & 3 & amalgam & firm & - & 9.49 \\
\hline 9 & & 20,000 & 2 & 3 & discrete & firm & 6 & 9.44 \\
\hline 10 & 0.40 & 20,000 & 2 & 3 & discrete & firm & - & 9.58 \\
\hline
\end{tabular}

a -325 mesh Indian Head lignite, as received.

b pH not taken.

c Moisture-free basis.

Ash content of as-received 1ignite was $14.63 \%$, and $11.03 \%$ for hot-waterdried lignite on a moisture-free basis. 


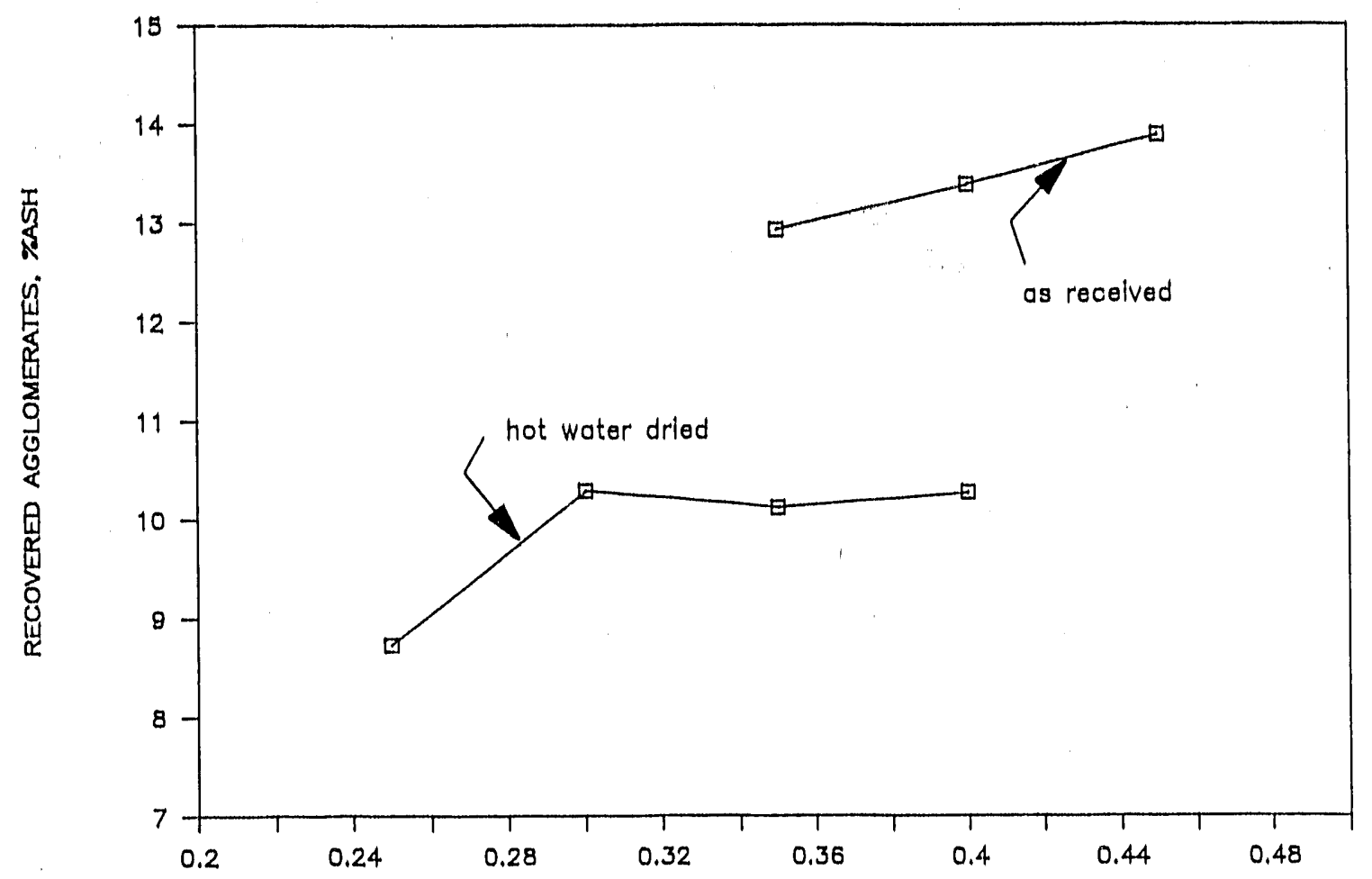

OIL TO COAL WEIGHT RATIO IN FEED, WT/WT

Figure 17. Percent agglomerate ash (moisture-free basis) as a function of solvent-to-coal ratio for -325 mesh as-received and hot-waterdried lignite. Mixing speed was 10,000 rpm for 3 minutes.

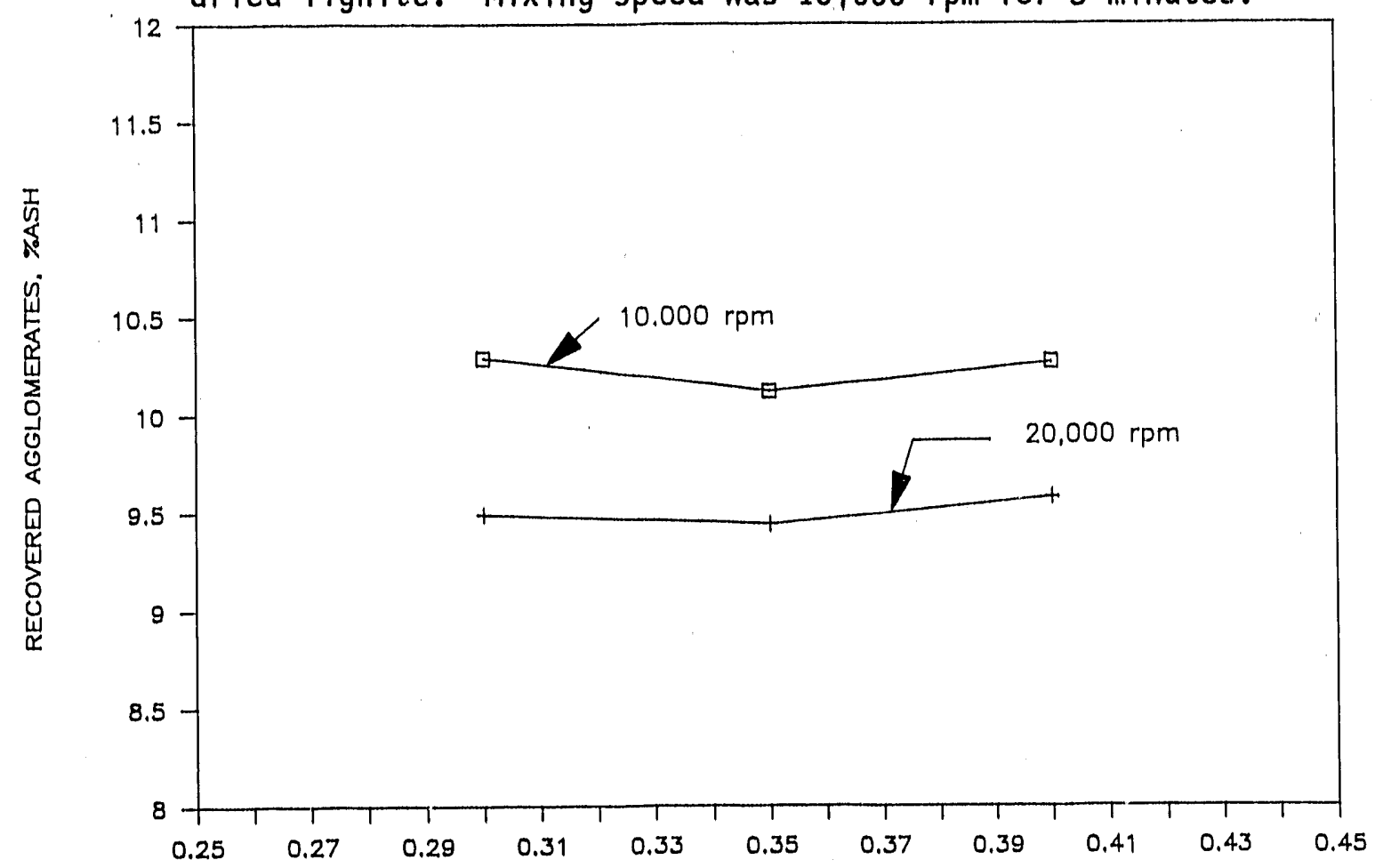

OIL TO COAL WEIGHT RATIO IN FEED, WT/WT

Figure 18. Percent agglomerate ash (moisture-free basis) as a function of solvent-to-coal ratio for 10,000 and $20,000 \mathrm{rpm}$ mixing speeds. Mandan Decant 011 in $p$-xylene binder and lignite were mixed for 3 minutes. 
TABLE 14

AGGLOMERATION RESULTS FOR 50 WT\% MANDAN DECANT BINDING OIL AND -325 MESH INDIAN HEAD LIGNITE, AS RECEIVED

\begin{tabular}{|c|c|c|c|c|c|c|c|c|}
\hline \multirow[b]{2}{*}{ Run \# } & \multirow{2}{*}{$\begin{array}{c}\text { Sol/Coa1 } \\
\text { Ratio }\end{array}$} & \multirow{2}{*}{$\begin{array}{l}\text { Mix Speed } \\
(\mathrm{rpm})\end{array}$} & \multirow{2}{*}{$\frac{\text { Mix Time }}{0 i 1-\mathrm{H}_{2} \mathrm{O}}$} & \multirow{2}{*}{$\frac{(\min )}{\text { Siurry }}$} & \multicolumn{2}{|c|}{ Agglomerates } & \multirow[b]{2}{*}{$\mathrm{pH}$} & \multirow{2}{*}{$\begin{array}{c}\text { \% Product } \\
\text { Ash }\end{array}$} \\
\hline & & & & & Type & Texture & & \\
\hline $\begin{array}{l}1^{a} \\
2^{a} \\
3^{a} \\
4 b \\
5^{b} \\
6^{b}\end{array}$ & $\begin{array}{l}0.40 \\
0.40 \\
0.40 \\
0.40 \\
0.40 \\
0.40\end{array}$ & $\begin{array}{l}15,000 \\
15,000 \\
15,000 \\
15,000 \\
15,000 \\
15,000\end{array}$ & $\begin{array}{l}2 \\
2 \\
2 \\
2 \\
2 \\
2\end{array}$ & $\begin{array}{l}6 \\
6 \\
6 \\
6 \\
6 \\
6\end{array}$ & $\begin{array}{l}\text { discrete } \\
\text { discrete } \\
\text { discrete } \\
\text { discrete } \\
\text { discrete } \\
\text { discrete }\end{array}$ & $\begin{array}{l}\text { firm } \\
\text { firm } \\
\text { firm } \\
\text { firm } \\
\text { firm } \\
\text { firm }\end{array}$ & $\begin{array}{l}-c \\
- \\
- \\
- \\
-\end{array}$ & $\begin{array}{l}12.73^{d} \\
11.94 \\
11.61 \\
12.92 \\
12.26 \\
12.98\end{array}$ \\
\hline
\end{tabular}

a 50 wt\% Mandan Decant oil in p-xylene binding oil.

b 50 wt\% Mandan Decant oil in Rectisol Naphtha binding oil.

c $\mathrm{pH}$ was not taken.

d Moisture-free basis.

Ash content of as-received lignite was $14.63 \%$, moisture-free basis.

\subsubsection{Conclusions}

Coals of finer particle sizes have been found to liberate ash more easily during agglomeration. UNDEMRC research seemed to bear this out, as the ash content of the -325 mesh bituminous coal was reduced more than that of the 70 wt\% -200 mesh coal, with ash reductions of $17.3 \%$ and $14.0 \%$, respectively.

Hot-water-dried lignite appeared to liberate ash more easily than did asreceived lignite. The ash content of the -325 mesh, hot-water-dried lignite was reduced $14.4 \%$ as compared to a reduction of $11.6 \%$ for the -325 mesh, asreceived lignite.

Results obtained during testing with Mandan Decant oil/rectisol naphtha solvent were not as satisfactory as the results obtained using Mandan Decant $0 i 1 / p-x y l e n e$. Ash reductions of -325 mesh, as-received Indian Head lignite using these two solvents were $13.1 \%$ and $17.4 \%$, respectively.

Higher mixing speeds $(16,000$ and $20,000 \mathrm{rpm})$ and longer mixing times (6 minutes) resulted in greater ash reductions, irrespective of coal type.

Agglomerates which were flocculate or discrete in form generally resulted in greater ash reductions than did amalgam agglomerates.

The solvent-to-coal ratio of a $50 \mathrm{wt} \%$ Mandan Decant $0 i 1$ in p-xylene mixture which yielded the greatest ash reductions when applied to either bituminous coal or lignite was 0.35 . 
Mandan Decant 0i1, which is a high-density 0i1, will agglomerate the various coal types only after extended periods of time. A medium-density, 50 wt\% mixture of Mandan Decant oil in either $p-x y$ lene or rectisol naphtha wi11 agglomerate the different coal types tested within several minutes.

\subsection{Papers Prepared for Presentation}

\subsubsection{Co-Processing}

A paper entitled "Coprocessing with Petroleum Resid and Martin Lake Lignite" was prepared for presentation at the Coal-0il Co-processing Symposium to be held at the Third Chemical Congress of North America sponsored by the American Chemical Society. The symposium will be held June 5-11, 1988, in Toronto. The abstract of the paper is as follows.

\section{ABSTRACT}

Petroleum resids have traditionally been overlooked as fuel sources despite their significant energy content. These products often contain iron, nickel, and vanadium in concentrations which rapidly deactivate or "poison" hydrogenation catalysts. Reacting petroleum resid with coal under iquefaction conditions or "coprocessing" has been proposed as an economic method for the removal of trace metals. Coprocessing involves the upgrading of a petroleum resid in a reaction with coal. While the resid acts as the liquefaction solvent some of the coal is converted to products, and the unconverted coal acts as a sink for metals. This paper will describe the results of tests to determine the increase in liquid product yields, and the reduction in the concentrations of trace metals achieved by coprocessing Arabian resid with Martin Lake lignite. Four batch autoclave tests were made using various catalysts and conditions. Distillable products comprising 45-60 wt\% of the individual product slurries were found to contain 2-8 ppm nickel and vanadium, and $9-41 \mathrm{ppm}$ iron.

\subsubsection{ChemCoal}

A paper entitled "ChemCoal Process Recycle Test/Indian Head Lignite" was prepared for presentation at the Fourteenth Biennial Lignite Symposium on the Technology and Utilization of Low-Rank Coals which was held in Dallas, Texas, from May 18-21, 1987. The abstract of the paper follows.

\section{ABSTRACT}

This report details work at the University of North Dakota Energy and Mineral Research Center (UNDEMRC) demonstrating the ChemCoal Process as applied to Indian Head lignite in a full solvent recycle to lined-out, steadystate operation. The ChemCoal Process uses chemical methods to transform coal into clean solid and liquid products. The process features low-severity conversion (temperatures less than $340^{\circ} \mathrm{C}$; pressures less than $12.4 \mathrm{MPa}$ (1800 psig)) of coal in a phenolic solvent, with an alkali promoter and carbon monoxide reductant. The work presented in this report was funded by the United States Department of Energy (DOE) through UND/DOE Cooperative Agreement DE-FC21-83FE60181, the Electric Power Research Institute (EPRI) Contract 2655-3, the University of North Dakota (UND), and Carbon Resources Inc. (CRI). 
A successful CPU recycle test to solvent lineout was achieved. Operation was maintained for 39 theoretical passes and was concluded voluntarily. The recycle test was primarily aimed at resolving potential process flaws identified in a 1985 report by Bechtel Group, Inc., "ChemCoal Process Evaluation Study." The recycle results showed:

- ChemCoal Process conversion averaged over $80 \%$ of MAF (moisture-and ash-free) coal and remained relatively constant.

- No loss in conversion occurred as process-derived solvent replaced start-up solvent in multiple recycles.

- Excess solvent (113\%) was generated under all conditions.

- Reductant consumption was below $2.0 \mathrm{wt} \%$ of the MAF coal as hydrogen gas.

\subsubsection{Agglomeration}

A paper entitled "Beneficiation of a Bituminous Codl and a Lignite Coal by Agglomeration Using Novel Binding 0ils" has been prepared for presentation at the Coal-0il Co-processing Symposium to be held at the Third Chemical Congress of North America sponsored by the American Chemical Society. The symposium will take place June 5-11, 1988, in Toronto. The abstract of the paper is as follows.

\section{ABSTRACT}

I1linois \#6 and buth as received and hot-water-dried Zap (Indian Head) North Dakota lignite were agglomerated with Mandan refinery decant oil containing either $p-x y$ lene or deodorized rectisol naphtha from the Great Plains Gasification Plant. The effectiveness of each of the binding oils on agglomeration was determined from ash reduction and organic recovery as a function of mixing speed, mixing time, particle size, and oil-to-coal ratio. Results indicated that, although the ash reduction was significant in the Mandan decant/rectisol naphtha binder for both coals, greater reduction was achieved with the Mandan decant/p-xylene. Higher mixing speeds, longer mixing times, smaller particle size, and binder to coal ratio of 0.35 gave the greatest ash reductions. Agglomeration time was shortened substantialiy when either $p-x y l e n e$ or rectisol naphtha was added to the Mandan decant in place of using Mandan decant alone as binder.

\subsection{CONCLUSIONS AND RECOMMENDATIONS}

\subsection{Task 1 - Co-Processing of Low-Rank Coal}

- Co-processing appears to have merit as a means of reducing catalystpoisoning metals concentrations in petroleum resids. In order to properly evaluate co-processing, both coal conversion and the extent of upgrading need to be assessed in terms of reaction cost and product value. In addition, a larger, more accurate analytical data base is required to validate the metals concentration values. 
- Pentane extraction of the product slurry provides a greater yield of usable product than distillation, and the pentane-soluble product contains iron, nickel, and vanadium in concentrations comparable to those of the distillate product.

- The use of a high-temperature first stage and a low-temperature second stage used for most bituminous coals does not appear to be as successful for L.RCs with respect to desired product composition as the low-temperature first-stage/high-temperature second-stage system.

- The most successful test in terms of product yield and composition appears to have been a low-temperature first-stage/high-temperature second-stage run made with $\mathrm{H}_{2} \mathrm{~S}$ as a reaction promotor.

\subsection{Task 2 - ChemCoal Process}

- The new reactor and downstream processing designs appear to have had the desired effects of shortening reactor residence times and producing Chemcoal product on 1 ine.

- The computer-controlled system accurately controls all liquid and gas flow rates and has resulted in a reduction in the number of personnel required for CPU operation.

- The new CPU layout has resulted in a significant decrease in odor in the work area.

- The ChemCoal solid prepared by acidification as shipped to Allison Gas Turbine Division for turbine testing appears to be a product that is superior in every respect to ultra-clean coal except that it contained $0.48 \%$ ash.

- ChemCoal processing results in a product with a smaller mean particle size than the feed due to the formation of floccules.

\subsection{Task 3 - Agglomeration Studies}

- Agglomeration of coals of finer particle size resulted in a greater reduction in ash content than did the agglomeration of larger particles of the same coal.

- Hot-water-dried lignite appeared to liberate ash more easily than did as-received lignite during agglomeration studies.

- A mixture of $50 \mathrm{wt} \%$ Mandan Decant $0 i 1$ and p-xylene appeared to reduce ash contents better during agglomeration than did a mixture of $50 \mathrm{wt} \%$ Mandan Decant $0 i 1$ and rectisol naphtha.

- Greater ash reductions for both coal types tested were realized with higher mixing speeds and longer mixing times. 
- When using the Mandan Decant oil/p-xylene mixture, a solvent-to-coal ratio of 0.35 resulted in the greatest reduction in the ash content of either bituminous coal or lignite.

- Agglomerates which are flocculate or discrete in form generally produce greater ash reductions than do amalgam agglomerates.

- Medium-density solvents seem to reduce ash more effectively during agglomeration than high-density solvents.

\subsection{FUTURE OBJECTIVES}

\subsection{Co-Processing of Low-Rank Coal}

The optimum product slate obtainable during LRC/resid co-processing will be determined. The results of the microreactor and batch autoclave testing performed during Years 1 and 2 of the program will be used to define the ranges for the parametric variables. The major variables include temperature, pressure, reducing gas composition, residence time, relative concentrations of coal and solvent, and catalyst systems. These independent variables will be evaluated in a statistically designed test matrix to provide mathematical models for predicting optimum yield structures.

Once the models have been developed, they will be used to predict the optimum conditions at which to operate the CPU during a long-term test (nominally 14 days in length) to verify the conditions chosen. The CPU test will determine the effects of long-term operation on the catalyst system, and will validate the yield structures obtained from the predictive model.

The results of the matrix evaluation will suggest which are the key variables, and, based on those recommendations, a limited number of samples that cover the widest range in conversions and yield structures will be submitted for detailed chemical analysis. The results of this analysis will be evaluated to determine significant contributions to coal solvation by the petroleum fractions of the solvent. The fate of specific hydrogen functionalities will also be examined.

The results of the test matrix will be compared to equivalent test points using an LRC-derived solvent. The LRC-derived solvent will be obtained either through operation to recycle lineout or from an earlier activity, such as the Chemcoal Process. If the ChemCoal distillate fraction is to be used, it will require cleanup and stabilization. This is, however, a simpler process than operating to recycle lineout and may therefore prove to be the more attractive of the two options.

\subsection{ChemCoal Process}

Further verification of the ChemCoal Process using higher-rank coals will be performed. The testing will be performed on the UNDEMRC CPU in the fully integrated, solvent-recycle mode of operation. This effort will include a statistically based parametric study to determine solvation step sensitivity as a function of various system parameters including pressure, residence time, catalyst loading, and reducing gas composition. This study is aimed at 
determining the optimum operating conditions for a select Powder River subbituminous coal, and how the variability of the solvation step affects the downstream processing loop.

A similar matrix will be run on a select midwestern bituminous coal. The goal of this test series is to verify the results of early processing testing which suggested that bituminous coals produced yields of chemical solids as good as or bet ter than LRCs.

Samples of ChemCoal will be prepared for testing within the Diesel Utilization program. Both liquid and slurry fuels will be tested.

An economic update for the ChemCoal Process will be performed. This will provide the credibility necessary for the private-sector funding needed to commercialize the process to occur.

A small mechanistic study will be performed to elucidate the mechanism of hydrogen transfer during the Chemcoal process. The microreactor system will be used for this testing.

\subsection{Agglomeration Studies}

Testing will continue to determine how to produce an easily handled, dry, low-ash LRC product using oil agglomeration techniques. Various solvents will be tested to improve on previously attained ash and moisture content reduction in LRCs. The use of additives to neutralize the oleophobic properties of the surface-functional groups on coal will be investigated.

\subsection{REFERENCES}

1. Liu, Y.A., editor, Physical Cleaning of Coal, Chapter 6, Marce 11 Dekker, New York, 1982.

2. Bhattacharyya, R.N., A.K. Muza, and G.G. Sarkar, "Role of Operating Variables in 011 Agglomeration of Coal," Agglomeration Seventy-Seven. 1977, Vol. 2, pp. 931-38.

3. Hazra, S.K., T.C. Rao, and G.G. Sarkar, "Effects of Process Variables on Size Distribution of 0 il Agglomerates of Fine Coal, "Coal Preparation, 1986, Vol. 3, pp. 77-87.

4. Bandopadhyay, P., "0il Agglomeration: The Emerging Technique for Fine Coal Beneficiation," Urja, 1984, Vol. 16, pp. 377-380.

5. Masologites, G.P., "Process for Agglomerating Coal," Patent No: US 4355999, Atlantic Richfield Co., December 20, 1978.

6. Hutton, C.A. and R.N. Gould, Cleaning up Coal: A Study of Coã Cleaning and Use of Cleaned Coal, p. 273, Ballinger Publishing Co., Cambridge, Mass., 1982. 
7. Labuschagne, B.C.J., "Relationships Between 011 Agglomeration And Surface Properties of Coal: Effect of $\mathrm{pH}$ and $0 \mathrm{il}$ Composition," Coal Preparation, 1986, Vo1. 3, pp. 113.

8. Pawlak, W., A. Turak, J. Janiak, B. Ignasiak, K. Szymocha, T. Ignasiak, and C. Rodkiewicz, "Agglomeration of Low-Rank Alberta Coals with Bridging Liquids Derived from Indigenous Bitumen and Heavy 0i1. Deposits," Proceedings of International Conference on Coal Science, Sydney, Australia, October 28, 1985. 
1. Program/Project Identiflcatlon No.

4. Name and Address

University of North Dakota Energy and Mineral Research Center Box 8213, University Station, Grand Forks, ND 58202

2. Program/Project Tille

Low-Rank Coal Direct Liquefaction \begin{tabular}{l|l}
\hline 7. FY & 8. Months or Quarters
\end{tabular}

87-88 Quarters

9. Cost Stalus a. Dollars Expressed in

Thousands

10. Cost Chart

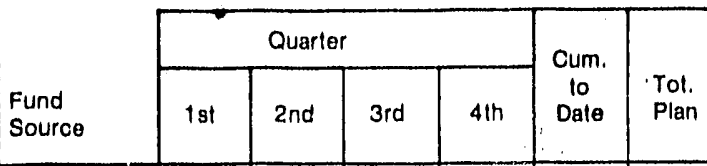

\begin{tabular}{l|l|l|l|l|l|l|l|}
\hline DOE & $\mathrm{P}$ & 183 & 191 & 186.7 & 167 & 727.7 & 727.7 \\
\cline { 2 - 6 } & & 117 & 175 & 61 & 155 & 608 \\
\hline
\end{tabular}

\begin{tabular}{|c|c|c|c|c|c|c|}
\hline Jut & A & 117 & 175 & 161 & \multicolumn{2}{|c|}{$155 \quad 608$} \\
\hline & $P$ & & & & & \\
\hline & A & & & & & \\
\hline & $P$ & & & & & \\
\hline & A & & & & & \\
\hline & $P$ & & & & & \\
\hline & A & & & & & \\
\hline Total $P$ & & 183 & 191 & 186.7 & 167 & 727.7 \\
\hline Total A & & 117 & 175 & 161 & 155 & 608 \\
\hline Varlafice & & 66 & 16 & 25.7 & 12 & 1119.7 \\
\hline
\end{tabular}

Total Planned Costs for Program/Project

$\$ 727.7$

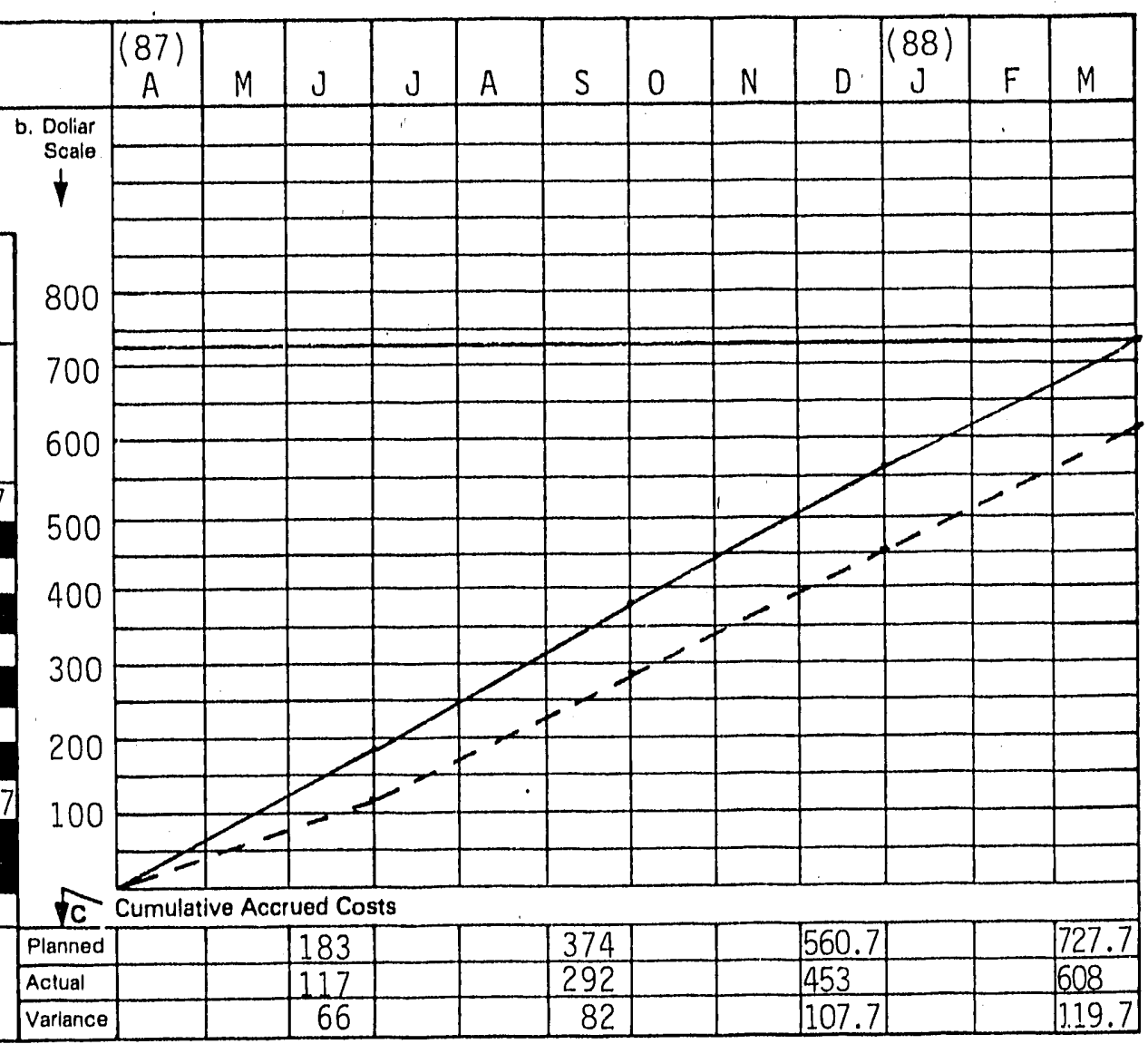

\begin{tabular}{|c|c|}
\hline \multirow[t]{2}{*}{ 11. Major Mllestone Status. } & Units Planned \\
\hline & Units Complete \\
\hline \multirow{2}{*}{\begin{tabular}{|l} 
Task 1. \\
Co-processing of \\
low-rank coal
\end{tabular}} & $P$ \\
\hline & C \\
\hline & $\mathbf{P}$ \\
\hline & C \\
\hline & $\mathbf{P}$ \\
\hline Task 2. ChemCoal & C \\
\hline & $\mathbf{P}$ \\
\hline & C \\
\hline & $\mathbf{P}$ \\
\hline & C \\
\hline . & $\mathbf{P}$ \\
\hline & C \\
\hline & $P$ \\
\hline & C \\
\hline & $\mathbf{P}$ \\
\hline & $\mathbf{C}$ \\
\hline & $\mathbf{P}$ \\
\hline 1 & $\theta$ \\
\hline & $\mathbf{P}$ \\
\hline & $\mathbf{C}$ \\
\hline & $\mathbf{P}$ \\
\hline & C \\
\hline & $\mathbf{P}$ \\
\hline & $\mathbf{C}$ \\
\hline & $\mathbf{P}$ \\
\hline
\end{tabular}

a3 b3 a4 a5 a6 b4, a

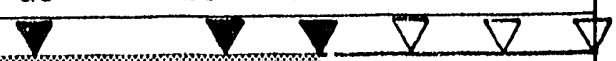

a2, a 3
$4-01-87$ through $3-31-88$

5. Program/Project Start Date $4-01-86$

6. Completlon Date $3-31-92$ 


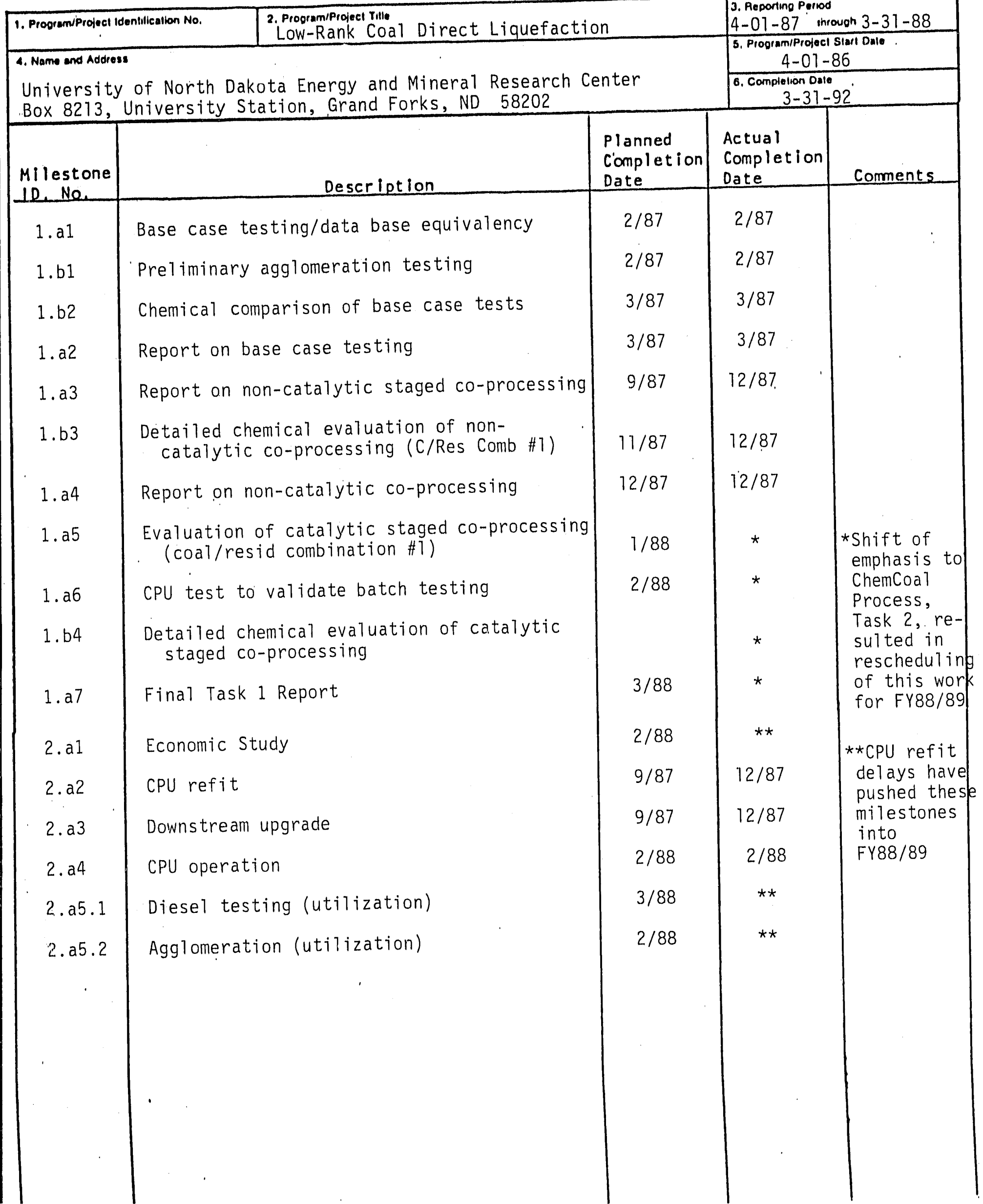




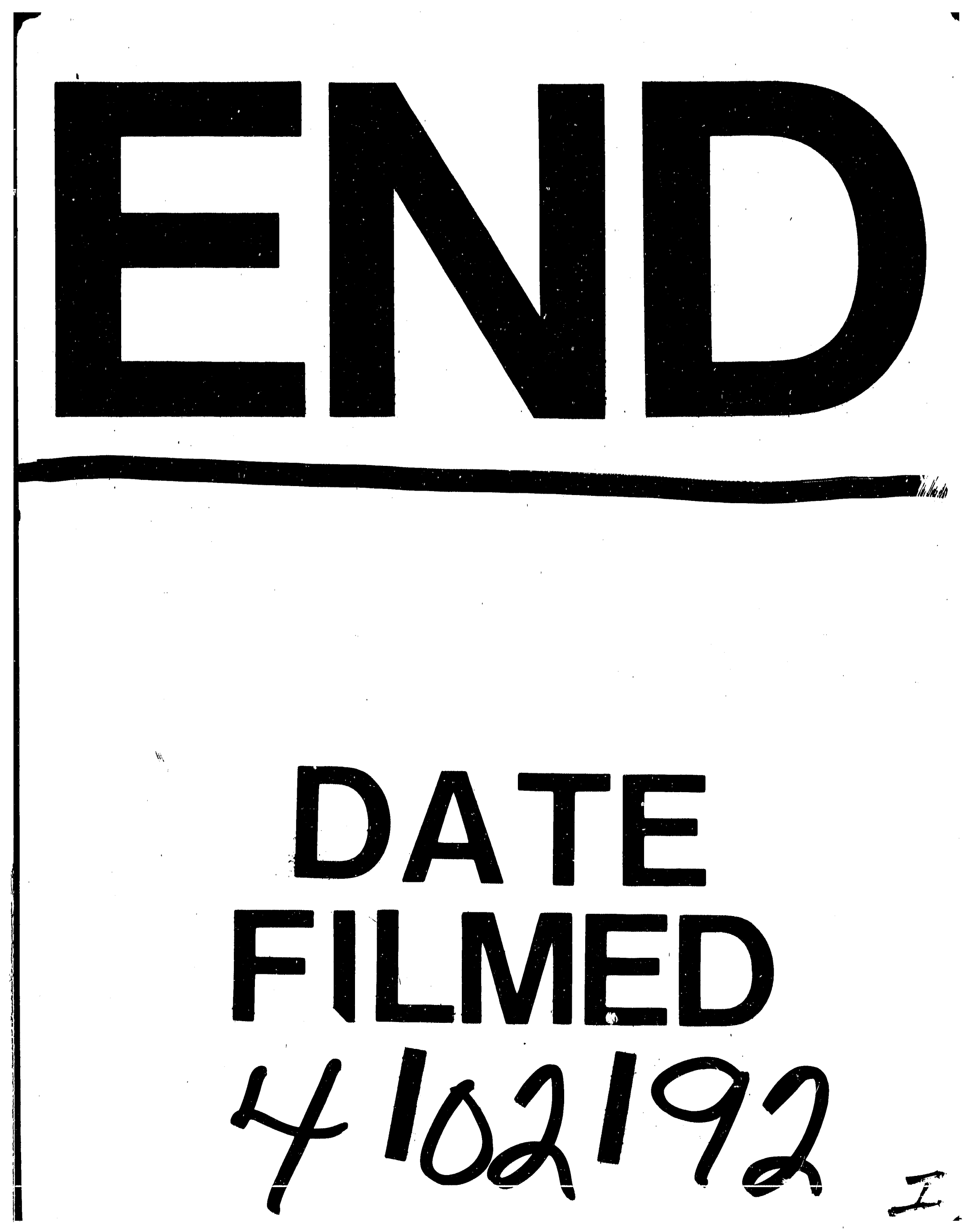




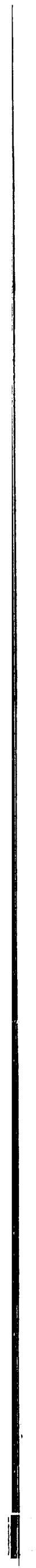

